\title{
Nomenclature for boranes and related species
}

Beckett, Michael; Brellochs, Bernd; Chizhevsky, Igor T.; Damhus, Ture; Hellwich, Karl-Heinz; Kennedy, John D.; Laitinen, Risto; Powell, Warren H.; Rabinovich, Daniel ; Vinas, Clara; Yerin, Andrey

\section{Pure and Applied Chemistry}

Published: 01/03/2020

Publisher's PDF, also known as Version of record

Cyswllt i'r cyhoeddiad / Link to publication

Dyfyniad o'r fersiwn a gyhoeddwyd / Citation for published version (APA):

Beckett, M., Brellochs, B., Chizhevsky, I. T., Damhus, T., Hellwich, K-H., Kennedy, J. D., Laitinen, R., Powell, W. H., Rabinovich, D., Vinas, C., \& Yerin, A. (2020). Nomenclature for boranes and related species. Pure and Applied Chemistry, 92(2), 355-381.

\footnotetext{
Hawliau Cyffredinol / General rights

Copyright and moral rights for the publications made accessible in the public portal are retained by the authors and/or other copyright owners and it is a condition of accessing publications that users recognise and abide by the legal requirements associated with these rights.

- Users may download and print one copy of any publication from the public portal for the purpose of private study or research.

- You may not further distribute the material or use it for any profit-making activity or commercial gain

- You may freely distribute the URL identifying the publication in the public portal?
}

Take down policy

If you believe that this document breaches copyright please contact us providing details, and we will remove access to the work immediately and investigate your claim. 


\title{
IUPAC Recommendations
}

Michael A. Beckett*, Bernd Brellochs, Igor T. Chizhevsky ${ }^{\dagger}$, Ture Damhus, Karl-Heinz Hellwich, John D. Kennedy, Risto Laitinen, Warren H. Powella, Daniel Rabinovich, Clara Viñas and Andrey Yerin

\section{Nomenclature for boranes and related species (IUPAC Recommendations 2019)}

https://doi.org/10.1515/pac-2018-0205

Received February 16, 2018; accepted July 6, 2019

\begin{abstract}
An appraisal of the current IUPAC recommendations for the nomenclature of boranes and related systems has been undertaken. New developments in the field have been investigated and existing nomenclature systems have been adapted to accommodate these new developments. The principal areas considered are stoichiometric and structural nomenclature (including heteroatom and metal-atom subrogation, as well as substitution of hydrogen), conjoined-cage species, supra-icosahedral systems, and sub-icosahedral non-standard structures. Elements of substitutive, additive, and replacement nomenclature systems have been integrated into individual names to address contentious problems in boron nomenclature that have been around for a long time.
\end{abstract}

Keywords: boranes; boron hydrides; carbaboranes; heteroboranes; IUPAC Chemical Nomenclature and Structural Representation Division; IUPAC Inorganic Chemistry Division; metallaboranes.

\section{CONTENTS}

BN-1 Introduction 356

BN-2 Nomenclature for neutral and anionic boron hydrides ................................................ 356

BN-3 Structural aspects of neutral boron hydrides (polyboranes) ...............................................357

BN-4 Substitution and skeletal replacement (subrogation) of neutral boron hydrides (polyboranes)

Article note: Sponsoring body: IUPAC Chemical Nomenclature and Structure Representation Division and the Inorganic Chemistry Division: see more details on page 379.

${ }^{\dagger}$ Deceased $22^{\text {nd }}$ May 2016.

aRetired.

*Corresponding author: Michael A. Beckett, School of Chemistry, Bangor University, Bangor, UK, e-mail: m.a.beckett@bangor.ac.uk.https://orcid.org/0000-0001-7531-2971

Bernd Brellochs: Boron Hydride Highlights, Neufahrn, Germany

Igor T. Chizhevsky: INEOS, Russian Academy of Sciences, Moscow, Russia

Ture Damhus: Østerbro, Copenhagen, Denmark

Karl-Heinz Hellwich: Beilstein-Institut zur Förderung der Chemischen Wissenschaften, Frankfurt, Germany. https://orcid.org/0000-0002-4811-7254

John D. Kennedy: School of Chemistry, The University of Leeds, Leeds, UK; and The Institute of Inorganic Chemistry of the Czech Academy of Sciences, Ǩež u Prahy, The Czech Republic. https://orcid.org/0000-0002-1480-1939

Risto Laitinen: Oulu University, Oulu, Finland

Warren H. Powell: Columbus, OH, USA

Daniel Rabinovich: University of North Carolina, Department of Chemistry, Charlotte, NC, USA

Clara Viñas: Institut de Ciencia de Materials de Barcelona (ICMAB-CSIC), Bellaterra, Spain. https://orcid.org/0000-0001-5000-0277

Andrey Yerin: Advanced Chemistry Development, Moscow, Russia. https://orcid.org/0000-0003-1523-0020 
BN-5 Substitution and skeletal replacement (subrogation) of anionic boron hydrides (polyhydridoborates)

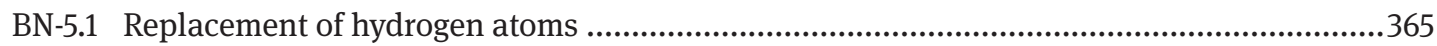

BN-5.2 Subrogation (skeletal replacement).........................................................................365

BN-6 Substitution and skeletal replacement (subrogation) of cationic boron hydrides (polyhydridoborons) ......................................................................................366

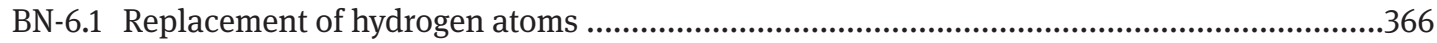

BN-6.2 Subrogation (skeletal replacement) ...........................................................................367

BN-7 New developments ..............................................................................................367

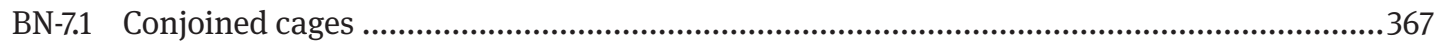

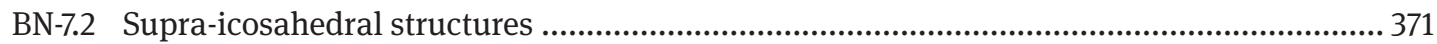

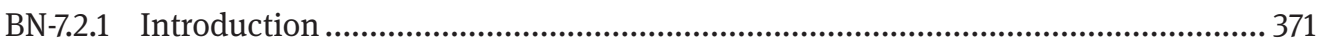

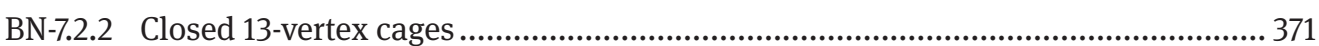

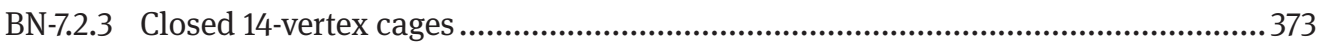

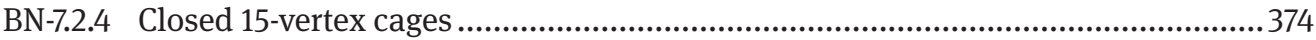

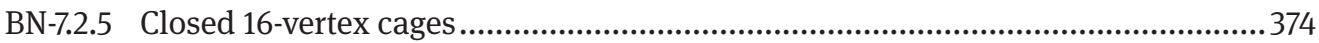

BN-7.2.6 Open supra-icosahedral cages.................................................................... 375

BN-7.3 Non-conventional deltahedral structures .............................................................. 376

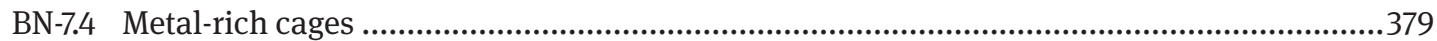

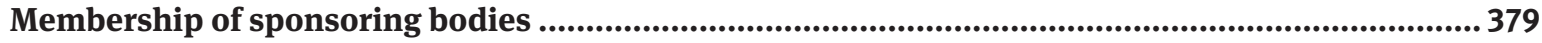

References..........................................................................................................................380

\section{BN-1 Introduction}

The most recent IUPAC recommendations concerning boron hydrides and related compounds appeared in 2005 [1a]. These recommendations reinforced earlier IUPAC recommendations in the subject area that had been published in 1990 [2a], but was essentially a 'holding' chapter, leaving new recommendations for a subsequent edition. The Introduction to the 1990 recommendations [2b] held that the area of boron nomenclature is 'contentious' and 'specialized' and that the relevant Chapter (I-11) "is presented as a survey of nomenclature of simpler boron systems because boranes are much discussed even at relatively elementary levels of chemistry, and because we wish to codify those basic principles which seem firmly established". Many of these recommendations were based on a Technical Report prepared in 1972 by R. Adams [3]. This 1972 report expanded on a brief chapter on the nomenclature of boron compounds in the 1970 recommendations [4a].

The purpose of this present document is to examine existing nomenclature recommendations to ensure that they can be clearly interpreted and to introduce new recommendations, incorporating new developments that have occurred in chemistry since these earlier reports. Each section is organized with numbered Recommendations followed by a more detailed commentary with relevant examples. Substituted boronhydride cages are named here by a nomenclature that encompasses features borrowed from both 'substitutive' and 'additive' IUPAC nomenclature systems.

\section{BN-2 Nomenclature for neutral and anionic boron hydrides}

Recommendation 1: Stoichiometric names for boron hydrides and additive names for boron-hydride anions, as described in the 1990 [2c] and 2005 [1b] recommendations, should continue to be used, but with one change: that the ligand name 'hydro' is replaced by 'hydrido' in the additive names. 
Recommendation 2: Ambiguous class names (e.g. 'borates', or 'carboranes'), are unacceptable and should no longer be used, even if in common use. Certain more explicit and less ambiguous class names (e.g. 'hydridoborates', 'oxidoborates', '1,2-dicarbadodecaboranes') are acceptable.

Stoichiometric or compositional names of boron hydrides are, as defined in earlier IUPAC recommendations, generally useful and in most cases easy to derive. Thus, neutral boron hydrides are named boranes, with a prefix to indicate the number of boron atoms present. This is then followed, in parentheses, by the number of hydrogen atoms present. Illustrative examples are diborane(6), pentaborane(9), and decaborane(14) for $\mathrm{B}_{2} \mathrm{H}_{6}$, $\mathrm{B}_{5} \mathrm{H}_{9}$, and $\mathrm{B}_{10} \mathrm{H}_{14}$, respectively.

Anions derived from boranes are named additively as hydridoborates. The number of hydrogen atoms (considered formally as hydride ligands) and boron atoms are specified by multiplicative prefixes and the name has the suffix 'ate', which is followed by the overall charge of the anion indicated in parentheses. The previously used ligand name 'hydro' has been changed to 'hydrido'. Thus, $\left[\mathrm{B}_{10} \mathrm{H}_{10}\right]^{2-}$ and $\left[\mathrm{B}_{12} \mathrm{H}_{12}\right]^{2-}$ are named decahydridodecaborate(2-) and dodecahydridododecaborate(2-), respectively.

Note: In substitutive nomenclature, anions formed by the addition of a hydride to a parent hydride are denoted by the suffix 'uide', with locant if relevant. For example, using this method, tetrahydridoborate(1-), $\left[\mathrm{BH}_{4}\right]^{\text {, }}$ becomes boranuide, an acceptable name, and $\left[\mathrm{CH}_{3} \mathrm{NHNH}_{3}\right]^{-}$is 2-methyl hydrazin-1-uide. This method could, in principle, be extended to other anionic borane systems, but this is not explored further in the present document.

Often, shortened names are observed in the chemical literature, e.g. decaborate(2-), carborane. The use of such names may be satisfactory if taken in context, but these abbreviated forms, when taken in isolation, are often misleading. This is particularly true for the term 'borates', which, in addition to its use for anionic boron hydrides, has also been traditionally used for boron-oxygen anions. It should be noted that 'borate' (in the singular) is a IUPAC-accepted (abbreviated or traditional) name used specifically for trioxidoborate(3-), following the general pattern for naming the fully dehydronated anions corresponding to the classical oxoacids (sulfate, phosphate, etc.). More informative generic terms, such as 'oxidoborates' and 'hydridoborates', should be used instead. See Section BN-4.2 for a short discussion on the use of 'carborane'. Overall, it is recommended that any shorthand usage in publications is preceded by the formal correct naming.

\section{BN-3 Structural aspects of neutral boron hydrides (polyboranes)}

Recommendation 3: The closed (closo) structures of deltahedra with 4-12 vertices, as defined and shown in Fig. 1 and the 1990 recommendations [2d], are used as the basis of boron-hydride nomenclature.

Recommendation 4: It is recommended that structural descriptors closo, nido, and arachno, as defined in the 1990 recommendations [2d], are retained (Fig. 2). However, the polyhedral shapes for hypho and klado are structurally difficult to visualize, and the use of these descriptors is no longer acceptable.

Recommendation 5: The structural descriptors for boron hydrides should be inserted into the name immediately before the prefix indicating the number of cage atoms.

Recommendation 6: Hydrogen atoms (and other groups) may be exo, endo, or in bridging ( $\mu$ ) positions, as defined in the 1990 recommendations [2e], and these descriptors are recommended.

Boranes generally have structures in which the boron atoms occupy vertices of closed or open deltahedra (triangulated polyhedra). These are often called 'clusters', although, in view of the fact that these deltahedra 


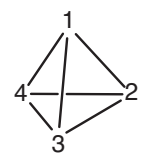

tetrahedron closo 4-vertex

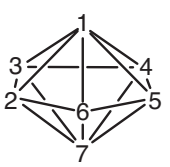

pentagonal bipyramid closo 7-vertex

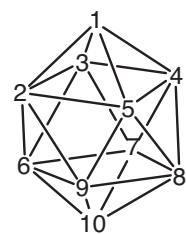

bicapped square antiprism (hexadecahedron) closo 10-vertex

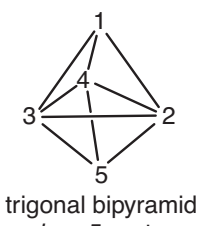
closo 5-vertex

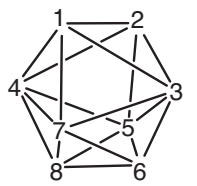

dodecahedron closo 8-vertex

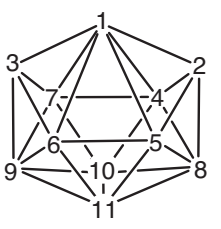

octadecahedron closo 11-vertex
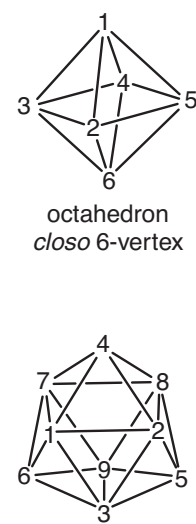

tricapped trigonal prism (tetradecahedron) closo 9-vertex

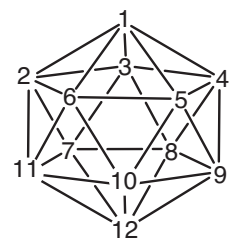

icosahedron closo 12-vertex

Fig. 1: Conventional triangulated polyhedra with 4-12 vertices, illustrating closo framework cage geometries, and showing numbering conventions. Note that reported experimental work sometimes uses different numbering.

do not contain interior atoms, 'cages' may be a more appropriate term. Both terms are in common use in the field, but for consistency 'cages' is used throughout this manuscript.

IUPAC recommendations [2d] have been introduced that describe cage structures classed as closed deltahedra (i.e. polyhedra that have triangular faces only) as closo and the more open deltahedral structures ('partially occupied' deltahedra) as nido, arachno, hypho, or klado, depending on the number of vertices missing from the parent closo cage structure. Thus, a deltahedron with one vertex missing is described as nido, one with two vertices missing is described as arachno, one with three vertices missing has been called hypho, and one with four vertices missing has been called klado. It is usually a vertex of highest connectivity (bonded to the greatest number of neighbours) that is removed to convert a closo structure to a nido structure, and an additional vertex adjacent to the previously highest connected vertex (thus located at the open face of the nido) is also removed to give rise to an arachno structure (Fig. 2). Removal of vertices other than those of highest-connectivity can result in structural isomers; in some cases, such other isomers have been called iso, neo, etc.

Cages that have had the hypho and klado descriptors are often difficult to visualize in terms of closed deltahedra from which vertices have been removed; often the relationship to a closo deltahedral parent is not clear, and such descriptors have often been given based on electron-counting schemes. Electron-counting rules [5] have been developed in parallel to these structural identifiers as an aid to understanding the structures of the boron hydrides (and their related compounds) based on their molecular (or ionic) formulae. However, there is a danger that these structural descriptors are based purely on conclusions drawn from electron-counting schemes, rather than observed structure, and therefore should not be used. This matter is dealt with in more detail in Section BN-7.3.

In the simpler boranes, hydrogen atoms are attached on each boron atom by bonds that are directed radially out from the centre of the polyhedron in positions defined as exo-terminal. Unless otherwise stated, the following convention is followed for all structural diagrams that represent molecules within this 


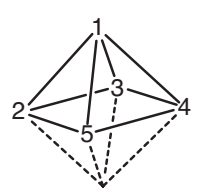

nido 5-vertex

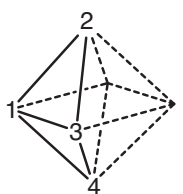

arachno 4-vertex

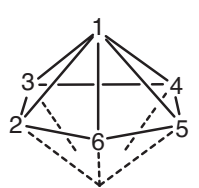

nido 6-vertex

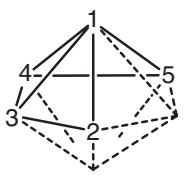

arachno 5-vertex

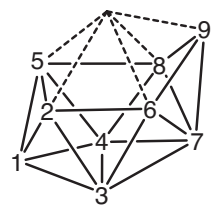

nido 9-vertex

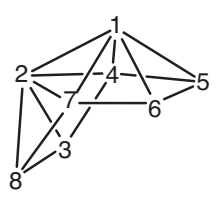

nido and arachno 8vertex*
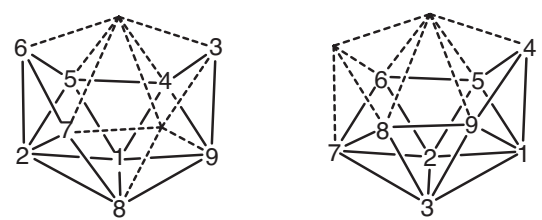

n-arachno 9-vertex* isoarachno (arachno) 9-vertex*

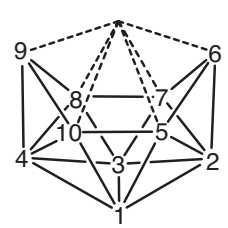

nido 10-vertex ${ }^{*}$

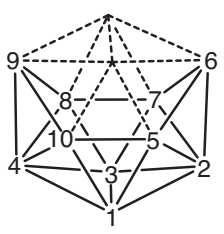

arachno 10-vertex*

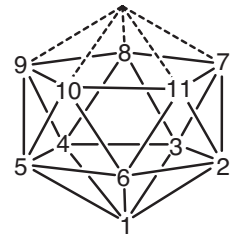

nido 11 -vertex

Fig. 2: Structures of commonly encountered classical Wadian nido and arachno polyhedral structures [5], illustrating their relationship with the closo structures of Fig. 1 and showing numbering conventions. The isoarachno 9-vertex structure is often referred to simply as arachno, and this is acceptable. Non-standard numbering (usually historically well-established) is denoted by *. The numbering of nido and arachno 10 -vertex structures are from ref. [3]; these are enantiomeric to those given in ref. [2d] and are now in current common usage.

manuscript: vertices specified by a 'number only' represent such $\{\mathrm{BH}\}$ units, whereas boron atoms with two terminal hydrogen-atoms or without terminal hydrogen-atoms, and non-boron atoms, are always shown by an element symbol (with superscript numbering) and with all attached substituent groups/ligands shown. Thus, for example, structure $1 \mathrm{~A}$ shows the connectivities of arachno- $\mathrm{B}_{4} \mathrm{H}_{10}$ and structure 1B illustrates how such a structure is represented within this manuscript. In the more open nido/ arachno structures, additional hydrogen atoms are also present and these either bridge two boron vertex atoms and are called bridging hydrogen atoms, or they may be associated solely with one boron atom and oriented approximately tangentially towards a 'missing' vertex, when they are described as endo-terminal hydrogen atoms (for example, both are illustrated in structure $\mathbf{1 A}$ and $\mathbf{1 B}$ ).<smiles></smiles>

$1 \mathrm{~A}$<smiles></smiles>

1B 
The descriptors exo, bridging, and endo are approved IUPAC descriptors in terminology and nomenclature for boron hydride cages [2e] and are in common usage. Some open-face hydrogen atoms have a 'partial bridging' character, i.e. intermediate between bridging $(\mu)$ and endo; it is recommended that such hydrogen atoms be described for nomenclature purposes either as bridging $(\mu)$ or as endo, with any perceived 'partial' character discussed in the relevant research paper.

For arachno systems, the removal of non-adjacent vertices can result in structures that have been called 'remote', e.g. the remote-arachno eleven-vertex structure of the $\left[\left(\mathrm{Ph}_{2} \mathrm{P}\right) \mathrm{B}_{10} \mathrm{H}_{12}\right]^{-}$anion (2). In general, the use of 'remote' is no longer acceptable and, in this particular case, a nomenclature based on arachno ten-vertex rather than arachno eleven-vertex can be used, with a $\left[\mu-6,9-\left(\mathrm{PPh}_{2}\right)\right.$-arachno- $\left.\mathrm{B}_{10} \mathrm{H}_{12}\right]$ - formulation as the basis for the full description. A similar bridging approach to nomenclature serves adequately for several other 'remote' examples. For more complex systems, a recourse to the 'debor system (see below in Section BN-7.2) may be necessary.

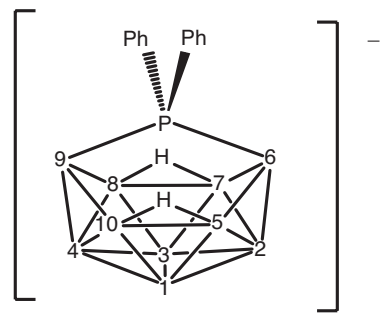

2

\section{BN-4 Substitution and skeletal replacement (subrogation) of neutral boron hydrides (polyboranes)}

\section{BN-4.1 Replacement of hydrogen atoms}

Recommendation 7: It is recommended that the numbering schemes, as shown in Figs. 1 and 2, and generally involving the 'clockwise-in-planes' system as defined in the 1990 recommendations [2f, 2g], should continue to be used. For exceptions see Recommendation 8.

Recommendation 8: Open 8-, 9- and 10-vertex systems (Fig. 2) have anomalous (i.e. not using the clockwisein-planes) numbering systems which are in current common usage, and it is recommended that this usage should continue $[2 \mathrm{~g}, 3]$.

Recommendation 9: In neutral polyborane species the replacement of a hydrogen atom by another atom or a monovalent group (a one-electron donor substitution) is denoted by using a substitutive prefix, and the replacement of a hydrogen atom by a neutral molecule (two-electron donor substituent) is denoted by prefixing an IUPAC name for the molecule to the polyborane name, indicating the coordinating atom by its italicized element symbol.

Note: The latter procedure resembles the treatment of ligands in additive nomenclature (except that a ligand in additive nomenclature does not replace an atom in an initial parent structure) and such donor substituents are called 'ligands' here. However, in the present document, when there are several identical and identicallycoordinating ligands attached to the same or different vertices in a polyborane cage, the ligand name is prefixed by a multiplicative prefix and by the locants of the vertices in question. 
Recommendation 10: In cases where a boron cage atom no longer has a terminal hydrogen atom (or another one-electron substituent group) attached to it the term 'dehydro' preceded by the corresponding locant must be used as a prefix immediately before the structural descriptor. The number in parentheses that counts hydrogen atoms in the parent structure still includes this 'missing' hydrogen atom.

Neutral polyborane cages are typified as having triangulated polyhedra of boron atoms, with each boron atom carrying an exo hydrogen atom. To avoid ambiguity and for accurate definition, numbering schemes for boron vertices (and associated exo substituents) have been developed (Figs. 1 and 2, Recommendation 7). The ten-vertex nido and arachno open structures based on the octadecahedron and the icosahedron with appropriate vertices removed are anomalous, both in that the members of each arachno/nido pair are topologically identical (Fig. 2), and in that their open faces are numbered sequentially as a 'unit' rather than in 'planes', as noted in the 1990 recommendations [2g]. The numbering system [3] as used for nido- and arachnodecaboranes has a long history and has much literature associated with it and this anomalous numbering is retained (Fig. 2 and Recommendation 8). The nido and arachno eight-vertex cage structures are also similarly anomalous in that they also have the same topology as each other, and in that the open face is numbered sequentially as a unit rather than in planes; again, because of ingrained historical usage, this 'anomalous' numbering is retained (Fig. 2 and Recommendation 8). Similar considerations must also apply to the historically established open-face numbering of the ' $n$-arachno' and 'iso-arachno' nine-vertex structures, of which the latter is commonly referred to simply as the arachno structure (Fig. 2).

Structures that are more open also have extra hydrogen atoms which may be bridging and/or endo hydrogen atoms and these may be defined by an adaption of the 'indicated-hydrogen' technique of organic substitutive nomenclature [6]. The position of these extra hydrogen atoms is indicated by attaching a locant to an italic ' $H$ ' (e.g. - $2 H$-) for a terminal hydrogen atom, and locants to the symbol ' $\mu H$ ' (e.g. 2,3- $\mu H$ etc.) for bridging hydrogen atoms. In this method, each boron centre carries at least one hydrogen atom and only hydrogen atoms additional to these are cited. It must be noted that these cited hydrogen atoms are not in addition to those included in the parenthetical hydrogen-atom count. E.g. arachno- $\mathrm{B}_{4} \mathrm{H}_{10}$ (1A and $\left.\mathbf{1 B}\right)$ may be named arachno-tetraborane(10) (stoichiometric/compositional name) or $2 H, 4 H-1,2-\mu H: 1,4-\mu H: 2,3-\mu H: 3,4-\mu H$-arachno-tetraborane(10) (indicated hydrogen-atom method). The 1990 edition of the IUPAC Inorganic rules [2h] introduced a shortened version for the citation of bridging hydrogen atoms, illustrated by the following format for arachno- $\mathrm{B}_{4} \mathrm{H}_{10}$, namely, $2 H, 4 H-1,2: 1,4: 2,3: 3,4$-tetra- $\mu H$-arachno-tetraborane(10). This shorter format is used in these recommendations. It should be noted for consistency within this document that bridging hydrogen atoms always follow after nonbridging hydrogen-atoms within a name. This is not a formal recommendation and a full consideration of this and the treatment of other modified prefixes will be the subject of further studies.

Many compounds that have cage structures can be described in terms of simple replacement of these exo or endo hydrogen atoms by various functional groups, i.e. formally, they are substituted compounds, as exemplified by organylboranes or halogenoboranes. Bridging hydrogen atoms may also be substituted and these are indicated using the bridging symbol $\mu$ preceded by the locants indicating the two boron-atom vertices that are bridged. The method for numbering boron vertices is robust and can also be extended to polyhedra with more than twelve vertices (see Section BN-7.2). The location of hydrogen atoms that are additional to one on each boron vertex can be specified by 'indicated hydrogens' [6].

The formal replacing group for a hydrogen atom may be either another substituent (one-electron group), e.g. $\mathrm{Cl}, \mathrm{CH}_{3}, \mathrm{Si}\left(\mathrm{CH}_{3}\right)_{3}$, etc., or a neutral molecule, e.g. $\mathrm{NMe}_{3}, \mathrm{PPh}_{3}, \mathrm{SMe}_{2}, \mathrm{NC}_{5} \mathrm{H}_{5}$, etc., which functions as a two-electron ligand. A 'one-electron group' is named as a substituent prefix in neutral polyboranes. A 'twoelectron group' is a neutral group and is cited as a neutral ligand. Substitution (replacement) by a substituent (one-electron group) is straightforward, and follows standard IUPAC substitutive nomenclature practice: derivatives are named based on the parent with the number of hydrogen atoms in parentheses being that of the parent. Thus substitution of an exo hydrogen atom at the 2-position of nido-decaborane(14) (3) by a methyl group results in 2-methyl-5,6:6,7:8,9:9,10-tetra- $\mu H$-nido-decaborane(14), (4). In a similar way, substitution of a bridging hydrogen atom in nido-pentaborane(9) by a trimethylsilyl group leads to $2,3-\mu$-(trimethylsilyl)2,3:2,5:3,4:4,5-tetra- $\mu H$-nido-pentaborane(9) (5). 

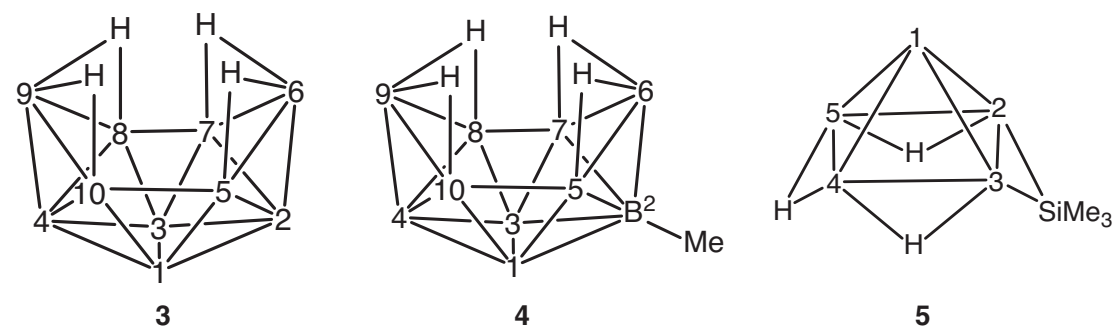

Substitutions that are not on symmetry axes or planes can lead to stereoisomers [3]. For example the monochloro derivative of nido-decaborane(14) that would simply, and generally reasonably, be described for most purposes as 5 -Cl-nido $-\mathrm{B}_{10} \mathrm{H}_{13}$, will, as generally prepared, in fact be a racemate. Separation of the enantiomers is rare, and although in principle these compounds could be named as under a system developed in organic chemistry for chiral fullerenes (see Section Fu-17, [7]), no formal recommendations on the topic are made here; these will need future further studies.

Substitution of hydrogen atoms by neutral two-electron donor groups can increase the number of electrons available for intra-skeletal bonding. For example, replacement of two one-electron hydrogen atoms by two two-electron ligands can in some cases increase the number of internal cage bonding electrons by a count of two and in some cases induce a formal closo to nido or nido to arachno structural change, i.e. it can induce a rearrangement of the cage to a more open structure. Thus, for example, the conversion of $\mathrm{B}_{10} \mathrm{H}_{14}(3)$ to 6,9-( $\left(\mathrm{SMe}_{2}\right)_{2} \mathrm{~B}_{10} \mathrm{H}_{12}$ (6) results in a nido-to-arachno conversion. Experimentally, the reaction of an excess of the two-electron ligand $\mathrm{SMe}_{2}$ with nido-decaborane(14) (3) leads to 6,9-( $\left.\mathrm{SMe}_{2}\right)_{2}$-arachno- $\mathrm{B}_{10} \mathrm{H}_{12}(6)$ with the elimination of two hydrogen atoms as $\mathrm{H}_{2}$. Because of this easy synthesis, such $\mathrm{B}_{10} \mathrm{H}_{12} \mathrm{~L}_{2}$ compounds, where $\mathrm{L}$ is a two-electron ligand, are often referred to as 'adducts' of nido $-\mathrm{B}_{10} \mathrm{H}_{14}$ despite them not being true adducts $[8,9]$. The 'indicated hydrogen' approach described above [6], gives the name 6,9-bis(dimethylsulfane-S)5,10:7,8-di- $\mu H$-arachno-decaborane(12) for 6.

In the 1990 recommendations [2i], compound 7, 1,2-( $\left.\mathrm{PMe}_{3}\right)_{2} \mathrm{~B}_{5} \mathrm{H}_{9}$, was given an addition compound name but here it is renamed 1,2-bis(trimethylphosphane- $\mathrm{P}$-1,2-didehydro- $2 \mathrm{H}, 3 \mathrm{H}, 4 \mathrm{H}, 5 \mathrm{H}-2,3: 4,5-\mathrm{di}-\mu \mathrm{H}$ pentaborane(11). Another familiar example, 4-( $\left.\mathrm{Me}_{2} \mathrm{~S}\right)$-arachno $-\mathrm{B}_{9} \mathrm{H}_{13}$, is named as 4-(dimethylsulfane-S)6H,8H-5,6:8,9-di- $\mu H$-arachno-nonaborane(13) (8). Similarly, in accord with Recommendation 10, the correct name for 1,10-( $\left.\mathrm{Me}_{2} \mathrm{~S}\right)_{2}$-closo- $\mathrm{B}_{10} \mathrm{H}_{8}(9)$ is 1,10-bis(dimethylsulfane-S)-1,10-didehydro-closo-decaborane(10).

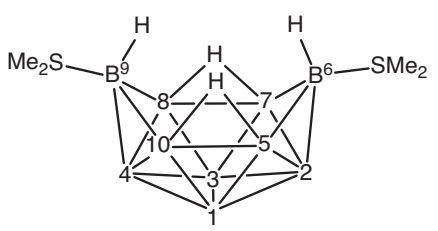

6

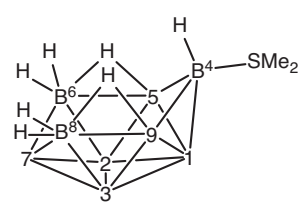

8
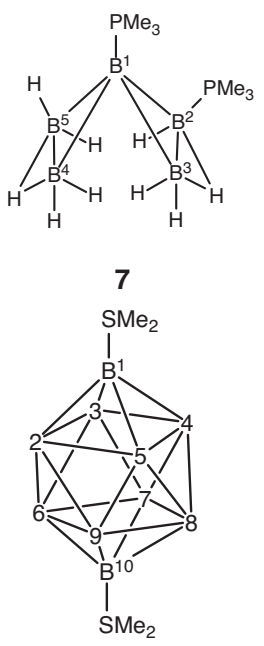

9

In terms of reactions, an addition of a two-electron ligand $\mathrm{L}$ with no other changes in empirical formula can indeed result in an adduct, e.g. $\mathrm{B}_{8} \mathrm{H}_{10}$ to $\mathrm{B}_{8} \mathrm{H}_{10} \mathrm{~L}$. However, in many instances this can increase by two the number of electrons available for skeletal bonding, e.g. a change from nido to arachno, as is the case in the 
$\mathrm{B}_{8} \mathrm{H}_{10}$ to $\mathrm{B}_{8} \mathrm{H}_{10} \mathrm{~L}$ conversion, and so the term 'adduct' can also be avoided here in terms of nomenclature. $\mathrm{A}$ caveat here is that in some transition-element metallaborane and metallaheteroborane compounds a twoelectron ligand may add to the metal-atom centre and not fundamentally affect the intracage bonding, so that the same cage structure (and the same skeletal bonding-electron count) are both retained. Since connectivities are being maintained, this latter example would correspond to an adduct as defined by IUPAC [8,9].

\section{BN-4.2 Subrogation (skeletal replacement)}

Recommendation 11: The structural descriptors should be inserted into the name immediately before the locant(s) and prefix(es) that indicate the subrogating atom(s) present in the cage.

Recommendation 12: Subrogating atoms are indicated by using conventional skeletal replacement 'a' terms, e.g. carba for carbon, thia for sulfur, and so on, and in the conventional descending-element order $(\mathrm{F} \rightarrow \mathrm{Rn})$ $[1 \mathrm{e}, 1 \mathrm{f}, 10]$, with each replacement term preceded by an appropriate locant.

Recommendation 13: The number of hydrogen atoms indicated in parentheses are those for the parent heteroborane, and this does not change on substitution.

Recommendation 14: Hydrogen atoms at transition-metal metal-atom centers in metallaboranes are named as hydrido ligands and are not included as part of the parent subrogated borane hydrogen-atom count in parentheses.

Boron atoms within a polyhedral cage framework may be replaced by atoms of other main-group elements or by atoms of transition-metal elements, with the structural integrity of the cage being retained. Such skeletal replacement is called 'subrogation'. The term subrogation is specific to skeletal replacements in boron hydride chemistry, and is not used elsewhere. The resulting structures are called 'heteroboranes' in accord with the usage in the 1990 recommendations [2j]. The common variant 'heteraboranes' is not acceptable anymore. On the other hand, boranes that have boron atoms subrogated by metallic main-group or transition-element atoms are termed 'metallaboranes' [2k].

Metallaheteroboranes with boron atoms subrogated by main-group and transition-element atoms are very common. The atom that subrogates the boron atom often (but not necessarily) has an exo group associated with it; exo groups may include hydrogen atoms, halogen atoms, organic groups, neutral molecules, etc $[1 \mathrm{e}, 10]$. Subrogating atoms are indicated using the conventional replacement terms in the conventional descending-element order $(\mathrm{F} \rightarrow \mathrm{Rn})$ e.g. oxa represents $\mathrm{O}$; thia S; aza N; phospha P; arsa As; carba C; sila Si; aura $\mathrm{Au}$; ferra $\mathrm{Fe}$; etc $[1 \mathrm{e}, 10]$. When there is a choice of numbering the senior heteroatom is assigned the lowest locant. The name of the subrogated compound is derived from the parent unsubrogated borane with the (unaltered) number in parentheses of the parent hetero/metallaborane retained as a suffix.

Thus closo-1,2- $\mathrm{C}_{2} \mathrm{~B}_{10} \mathrm{H}_{12}$ is named as a dodecaborane with two boron-atom vertices replaced by carbon atoms and with twelve hydrogen atoms in total, i.e. closo-1,2-dicarbadodecaborane(12). This last species, closo-1,2-dicarbadodecaborane(12), has been variously referred to as closo-1,2-dicarborane, ortho-dicarborane, dicarborane - and even simply carborane - as well as other variants. This casual approach to nomenclature in closo-dicarbadodecaborane(12) chemistry severely compromises specific data-base searches and retrievals (see Section BN-2, and Recommendation 2).

IUPAC convention [2l, 3, 4b] traditionally places the structural descriptor (i.e. closo, nido, etc.) right in front of the borane segment of the name. However, Recommendation 11 now focuses on the 'cage' (and what it contains) and places the descriptor before the cage name, e.g. closo-1,2-dicarbadodecaborane(12) rather than the previously accepted 1,2-dicarba-closo-dodecaborane(12). For the purpose of nomenclature, there is an implied hydrogen atom on every boron-atom or carbon-atom vertex within subrogated polyboranes, while all other heteroatoms or metallic atoms do not have implied hydrogen atoms. This correctly highlights and describes the hydrogen-atom count (including heteroatom substituents) for the numerical suffix in 
parentheses for the heteroborane parent. Therefore, the compounds arachno-6,9- $\mathrm{C}_{2} \mathrm{~B}_{8} \mathrm{H}_{14}(\mathbf{1 0})$ and arachno6,9- $\mathrm{S}_{2} \mathrm{~B}_{8} \mathrm{H}_{10}$ (11) are named as $6 H, 9 H$-5,10:7,8-di- $\mu H$-arachno-6,9-dicarbadecaborane(14) and 5,10:7,8-di- $\mu H$ arachno-6,9-dithiadecaborane(10), respectively.

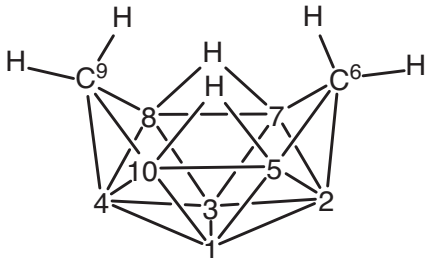

10

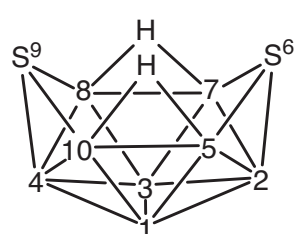

11

The correct name for 3-Me-closo-1,2- $\mathrm{C}_{2} \mathrm{~B}_{10} \mathrm{H}_{11}$ (12) is 3-methyl-closo-1,2-dicarbadodecaborane(12) (Recommendation 13), since the parent heteroborane is closo-1,2- $\mathrm{C}_{2} \mathrm{~B}_{10} \mathrm{H}_{12}$.

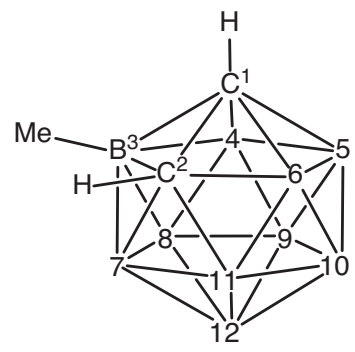

12

IUPAC recommendations from 1990 briefly describe a method for the naming of metallaboranes possessing exo-hydrido ligands [2m]. Here it is 'normally not assumed', when determining the number to be placed in parentheses, that metal atoms would carry hydrogen atoms in the unmodified parent, and hence any such hydrogen atoms do need to be specified. With this system, exo-hydrido ligands to transition-metal atoms are not included in the hydrogen-atom count for the parent metallaborane, and are indicated as hydrido ligands at the metal centre. Substitution on boron (or heteroatom) would retain the parent hydrogen-atom count, as is accepted for boranes and heteroboranes. This is illustrated by the following examples from nido-6-rhenadecaborane chemistry [11]: 6,6,6-( $\left.\mathrm{PMe}_{2} \mathrm{Ph}\right)_{3}-6-\mathrm{H}-$-nido-6- $\mathrm{ReB}_{9} \mathrm{H}_{13}(13)$ and 2-Cl-6,6,6-( $\left.\mathrm{PMe}_{2} \mathrm{Ph}\right)_{3}-6-\mathrm{H}$-nido-6- $\mathrm{ReB}_{9} \mathrm{H}_{12}$ (14) are named 6,6,6-tris[dimethyl(phenyl)phosphane- $P$ ]-6-hydrido5,6:6,7:8,9:9,10-tetra- $\mu H$-nido-6-rhenadecaborane(13), and 2-chloro-6,6,6-tris[dimethyl(phenyl)phosphaneP]-6-hydrido-5,6:6,7:8,9:9,10-tetra- $\mu H$-nido-6-rhenadecaborane(13), respectively.

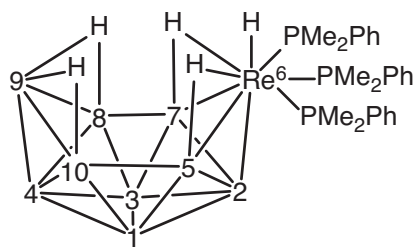

13

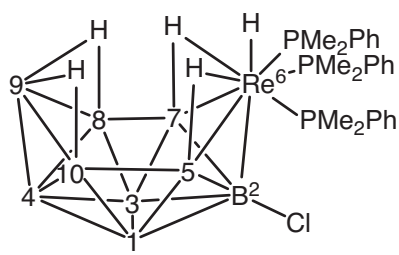

14

There are many metallaborane and metallaheteroborane cage compounds that include neutral molecules (two-electron-donor substituents) that formally replace exo B-H hydrogen atoms. Thus, 6-Cl-2,6,6-( $\left.\mathrm{PMe}_{2} \mathrm{Ph}\right)_{3}$ 6-H-nido-6- $\mathrm{ReB}_{9} \mathrm{H}_{12}$ (15, an isomer of 14) can be named 6-chlorido-2,6,6-tris[dimethyl(phenyl)phosphane- $\mathrm{P}$ 6-hydrido-2-dehydro-5,6:6,7:8,9:9,10-tetra- $\mu H$-nido-6-rhenadecaborane(13). It should be noted that 'dehydro' should be part of the parent structure and thus cited immediately before the structural descriptor (which 
includes 'indicated hydrogen'), whereas 'hydrido' is cited alphabetically together with other ligand and/or substitutive prefixes.

Many complexes in heteroborane and metallaheteroborane chemistry that are also in this category are the so-called 'charge-compensated' complexes, e.g. 7-( $\left.\mathrm{SMe}_{2}\right)-3-\mathrm{H}-3,3-\left(\mathrm{PPh}_{3}\right)_{2}-$ closo-1,2,3- $\mathrm{C}_{2} \mathrm{RuB}_{9} \mathrm{H}_{10}(\mathbf{1 6})$ is named 7-(dimethylsulfane-S)-3-hydrido-3,3-bis(triphenylphosphane- $P$ )-7-dehydro-closo-1,2-dicarba-3-ruthenadodecaborane(11). Since 'charge compensation' is a notional concept, there is no need for any anionic nomenclature (Sections BN-2 and BN-5).

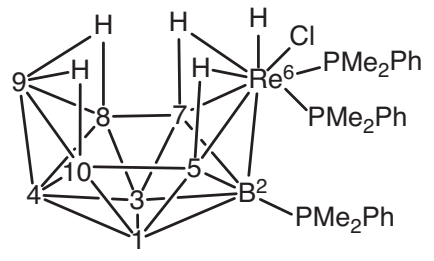

15

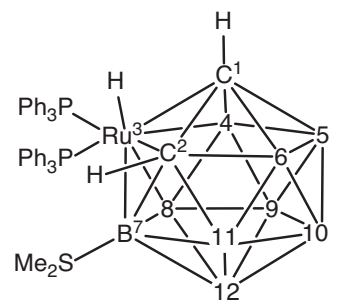

16

\section{BN-5 Substitution and skeletal replacement (subrogation) of anionic boron hydrides (polyhydridoborates)}

\section{BN-5.1 Replacement of hydrogen atoms}

As noted in Section BN-2, anionic polyboron hydride derivatives (polyhydridoborates) are named additively, resulting in the 'ate' suffix instead of the 'ane' suffix, immediately followed by the charge number in parentheses. The structural descriptors and numbering remain the same as for the corresponding neutral polyboranes. All hydrogen atoms are described as 'hydrido' ligands. The use of locants is not required if all boron sites carry a terminal hydrogen atom or if their locations are unambiguous. Therefore, closo- $\left[\mathrm{B}_{6} \mathrm{H}_{6}\right]^{2-}$ is named hexahydrido-closo-hexaborate(2-). Bridging hydrogen atoms are denoted by the prefix, $\mu$-hydrido, together with appropriate locants, e.g. 2,3- $\mu$-hydrido. All other groups are also named as ligands, e.g. 2-methyl-nido-decaborane(14) (4), 2-Me-nido- $\mathrm{B}_{10} \mathrm{H}_{13}$, can be dehydronated by losing a bridging hydrogen atom as a hydron to form an anion $\left[2-\mathrm{MeB}_{10} \mathrm{H}_{12}\right]^{-}$. This is named, in a shortened form, nonahydrido-5,6:6,7:8,9-tri- $\mu$-hydrido-2-methanido-nido-decaborate(1-), since the positions of the terminal hydrogen-atoms are unambiguous.

\section{BN-5.2 Subrogation (skeletal replacement)}

Recommendation 15: In the names of subrogated polyhydridoborates, the order of citation of the elements at cage vertices should follow the conventional descending-element order $(\mathrm{F} \rightarrow \mathrm{Rn})$ and subrogating atoms should be indicated using the conventional replacement 'a' terms [1e, 10], e.g. carba for carbon, thia for sulfur etc.

Note: This ordering of the elements in the names of anionic subrogated polyboranes is the opposite order of citation of central atoms in additive nomenclature.

As an example, the anion [nido-7,8- $\left.\mathrm{C}_{2} \mathrm{~B}_{9} \mathrm{H}_{11}\right]^{2-}$ (colloquially also known as the 'dicarbollide' anion) (17) is named undecahydrido-nido-7,8-dicarbaundecaborate(2-). 


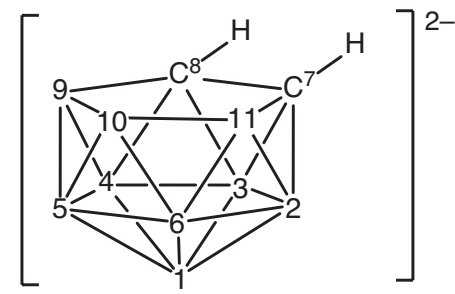

17

The method can be used to name polyhydridoborate anions with further subrogation by using the element order, as specified in Recommendation 15. Thus, [6,9- $\left.\mathrm{SCB}_{8} \mathrm{H}_{11}\right]^{-}$(18) can be correctly named as 1,2,3,4,5,7,8,9,9,10-decahydrido-5,10- $\mu$-hydrido-arachno-6-thia-9-carbadecaborate(1-) (although [6,9- $\left.\mathrm{CSB}_{8} \mathrm{H}_{11}\right]^{-}$, with carbon and sulfur numbering interchanged, has been used in the literature) and [3,3,3-(CO) $-1,2,3-$ $\left.\mathrm{C}_{2} \mathrm{MoB}_{9} \mathrm{H}_{11}\right]^{2-}$ is named 3,3,3-tricarbonylundecahydrido-closo-1,2-dicarba-3-molybdadodecaborate(2-) (19).

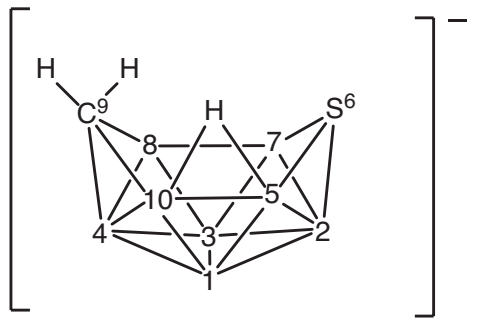

18

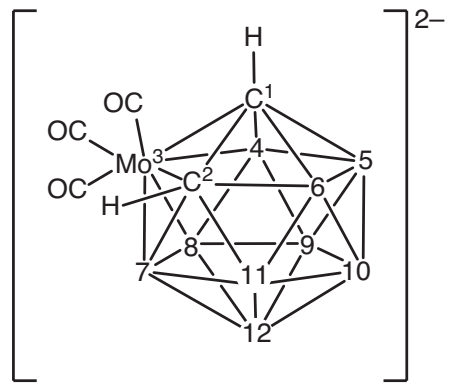

19

\section{BN-6 Substitution and skeletal replacement (subrogation) of cationic boron hydrides (polyhydridoborons)}

\section{BN-6.1 Replacement of hydrogen atoms}

Recommendation 16: Cationic boron hydrides are named as polyboron $(n+)(n=$ charge on the cation) cages as described in an IUPAC publication [4c]. It is further recommended that the descriptors and numbering systems, as applied to neutral (uncharged) polyboranes and anionic polyhydridoborates, are also used for polyboron $(n+)$ cations, and that all substituents, including hydrogen atoms, are named as ligands.

Cationic boron-hydride species are uncommonat the time of this report, but despite this, suitable nomenclature needs to be available for such compounds. A system for naming cationic polyboron cages is described in IUPAC recommendations $[2 \mathrm{n}, 3,4 \mathrm{c}]$, where $\left[\mathrm{B}_{10} \mathrm{H}_{7}\left(\mathrm{NH}_{3}\right)_{3}\right]^{+}$is named as triammineheptahydrodecaboron(1+). It should be noted that the name is formulated as a polyboron derivative, and it is immediately followed by the charge in parentheses. IUPAC now uses 'hydrido' rather than 'hydro' when naming hydride ligands in additive nomenclature and triammineheptahydridodecaboron(1+) is now the correct name. To be consistent with anionic cages, structural descriptors and numbering schemes are again needed in order to specify skeletal structures and substituted positions and numbering systems remain the same as those used for neutral (uncharged) polyboranes and (negatively charged) polyhydridoborates (Recommendation 16). Again, all hydrogen atoms are described as hydrido ligands, bridging hydrogen atoms are denoted as $\mu$-hydrido ligands together with appropriate locants, e.g. 2,3- $\mu$-hydrido, and all substituent groups on boron-atom sites are named as ligands e.g. chlorido, triphenylphosphane- $P$, etc. 
The cations present in the salts $\left[1,7,9-\left(\mathrm{Me}_{2} \mathrm{~S}\right)_{3}\right.$-closo $\left.-\mathrm{B}_{12} \mathrm{H}_{9}\right]\left[\mathrm{BF}_{4}\right]$ and $\left[1,2,10-\left(\mathrm{Me}_{2} \mathrm{~S}\right)_{3}-\right.$ closo $\left.-\mathrm{B}_{10} \mathrm{H}_{7}\right]\left[\mathrm{BF}_{4}\right]$ are shown in structures 20 and 21, respectively. These cations can be named as 1,7,9-tris(dimethylsulfane-S)2,3,4,5,6,8,10,11,12-nonahydrido-closo-dodecaboron(1+) and 1,2,10-tris(dimethylsulfane-S)-3,4,5,6,7,8,9-heptahydrido-closo-decaboron(1+), respectively.

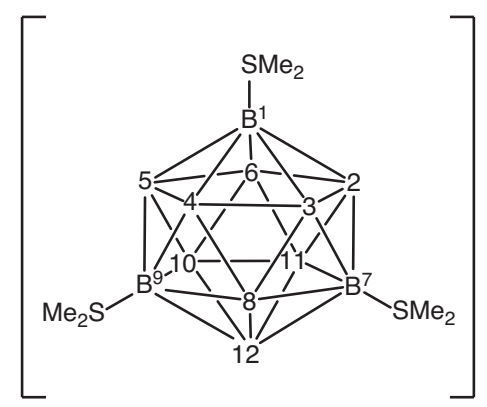

20

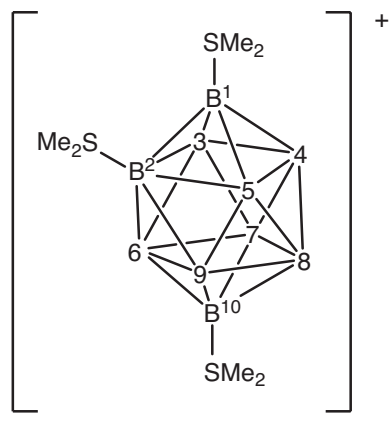

21

\section{BN-6.2 Subrogation (skeletal replacement)}

Recommendation 17: Subrogated polyboron cations are named as polyboron $(n+)$ derivatives and subrogating atoms are indicated by using conventional replacement ' $a$ ' terms (e.g. carba for carbon) cited in the conventional descending-element order $(\mathrm{F} \rightarrow \mathrm{Rn})[1 \mathrm{e}, 10]$. The structural descriptors and numbering remain the same as for the neutral polyboranes and polyhydridoborates and all substituents, including hydrogen atoms, are named as ligands.

The cation observed in $\left[2,2-\left(\mathrm{PMe}_{2} \mathrm{Ph}\right)_{2}-7-\left(\mathrm{PPh}_{3}\right)\right.$-closo-1,2-TePdB $\left.{ }_{10} \mathrm{H}_{9}\right]\left[\mathrm{BF}_{4}\right]$ can be named as 2,2-bis[dimethyl(phenyl)phosphane- $P$ ]-3,4,5,6,8,9,10,11,12-nonahydrido-7-(triphenylphosphane- $P$ )-closo-1-tellura-2-palladadodecaboron(1+) (22) [12].

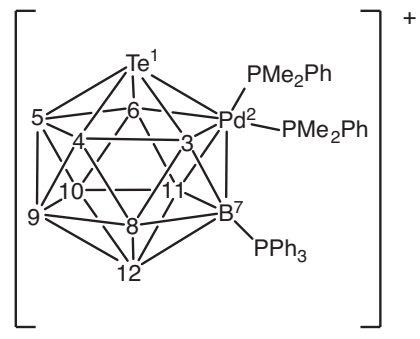

22

\section{BN-7 New developments}

\section{BN-7.1 Conjoined cages}

Recommendation 18: The term commo is recommended [20] and complemented by the use of the structural terms dicommo and tricommo to describe conjoined polyhedral cages with 1, 2, or 3 atoms in common. The structural term should be placed as an infix in the name and surrounded by locants and the name of each cage in square brackets as [borane]- $a^{\prime}$-commo- $x$-[borane], [borano]- $a^{\prime}, b^{\prime}$-dicommo- $x, y$-[borane], or [borano]$a^{\prime}, b^{\prime}, c^{\prime}$-tricommo- $x, y, z$-[borane], respectively. 
Compounds that contain two or more borane, heteroborane, metallaborane, etc., cages that are joined together exhibit inter-cage conjunctions of varying intimacy. The cages can be joined by a linking (bridging) moiety, or by a $\sigma$-bond, or by using a more intimate inter-cage 'fusion' with one, two, or more atoms held in common between two cages. The term conjuncto has been used as a general term for all such species [2o], but as the chemistry has progressed it now lacks specificity for nomenclature purposes and we recommend that its unqualified usage be discontinued in terms of nomenclature. The only previously recommended IUPAC term in this category is commo for cages with one atom in common [2o].

Polyboron cages linked by a $\sigma$-bond should be named by the ring assembly methodology of organic nomenclature or by substituting one polyborane cage into another polyboron cage. Thus, the $\sigma$-linked $\left(\mathrm{B}_{10} \mathrm{H}_{13}\right)\left(\mathrm{B}_{10} \mathrm{H}_{13}\right)(23)$ is named 2-[5,6:6,7:8,9:9,10-tetra- $\mu H$-nido-decaboran(14)-6-yl]-5,6:6,7:8,9:9,10-tetra- $\mu \mathrm{H}$ nido-decaborane(14).

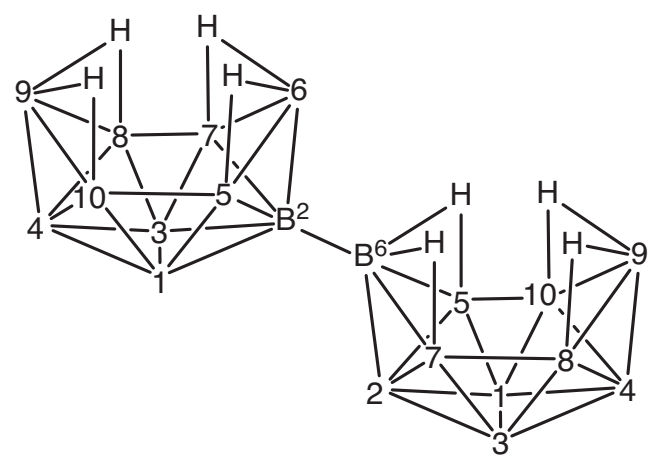

23

The term commo has been used for the description of two-cage assemblies that can be regarded structurally as consisting of two definable cages that are conjoined or fused with one atom held in common [20, 3] similar to spiro compounds in organic chemistry. The commo nomenclature for the one-atom-in-common case is well entrenched in the literature and should be retained and extended to cages involving two atoms in common and three atoms in common. Hydrogen atoms attached to common atoms need to be cited, since it is otherwise assumed that they do not have hydrogen atoms attached in the count used for the number in parenthesis for the parent. Few examples are known in which the common atom is boron, but the term has been used extensively to describe the trivially-named 'bisdicarbollide' complexes of transition elements $\mathrm{M}$, of nominal formulation $\left\{\mathrm{M}\left(\mathrm{C}_{2} \mathrm{~B}_{9} \mathrm{H}_{11}\right)_{2}\right\}$ (24). A terminal polyboron cage is given unprimed numbers and other polyboron cages are given serially primed numbers. A symmetrical fused closo-1,2,3- $\mathrm{C}_{2} \mathrm{MB}_{9} \mathrm{H}_{11}$ system, exemplified by $\mathbf{2 4}$, is named as a 3,3'-commo-bis[closo-1,2-dicarba-3-metalladodecaborane(11)], but an alternative name (Recommendation 18) is [closo-1', $2^{\prime}$-dicarba-3'-metalladodecaborane(11)]-3'-commo3-[closo-1,2-dicarba-3-metalladodecaborane(11)] and this infix format should be used for non-symmetrical commo systems. Thus, for example, the $\left[\left(\mathrm{C}_{2} \mathrm{~B}_{9} \mathrm{H}_{11}\right) \mathrm{Fe}\left(\mathrm{C}_{2} \mathrm{~B}_{9} \mathrm{H}_{11}\right)\right]^{-}$anion $\left(\mathrm{M}=\mathrm{Fe}^{(\mathrm{III})}\right.$, structure 24$)$ is named as 3,3'-commo-bis[undecahydrido-closo-1,2-dicarba-3-ferradodecaborate](1-), since it is symmetrical; the corresponding format [undecahydrido-closo-1',2'-dicarba-3'-ferradodecaborate]-3'-commo-3-[undecahydridocloso-1,2-dicarba-3-ferradodecaborate](1-) should also be used for non-symmetrical systems.

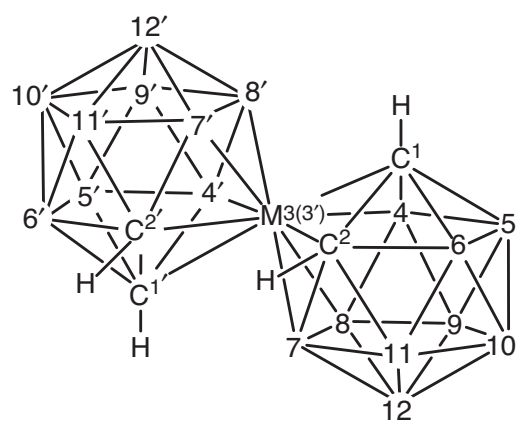


An important feature of the 'biscarbollide' and related one-metal-atom-in-common systems is the mutual contrarotation of the two subcages; a number of rotamers can therefore exist, and this can engender the usage of terms such as gauche, transoid, cisoid, eclipsed, gauchoid, etc. Rotamer considerations, when relevant, are usually dealt with adequately as they arise in the scientific publications that report them; they are beyond the scope of these Recommendations. One possibility would be to define the structure based on the eclipsed conformation of lowest-numbered vertices ( $\mathrm{C} 2$ and $\mathrm{C} 2$ ' in $\mathbf{2 4}$ being those that are eclipsed), and introduce a clockwise rotation angle into the nomenclature relative to the nominally static basis cage (i.e. the unprimed cage).

Compounds that contain two or more cages, with individual cages that are joined or fused to each other with two or more atoms held in common, are often referred to as 'macropolyhedral' species [13-17], a trivial, but often useful generic term, but with no role in formal nomenclature.

For cages containing a two-atoms-in-common fusion (often known as edge-fusion), which is a feature of the bulk of the so-far-reported 'macropolyhedral' boranes, metallaboranes, and heteroboranes, (particularly, in the last category, thiaboranes), the term 'dicommo' is introduced (Recommendation 18).

The two known isomers of $\mathrm{B}_{18} \mathrm{H}_{22}$ are named as $\left[5^{\prime}, 6^{\prime}: 8^{\prime}, 9^{\prime}: 9^{\prime}, 10^{\prime}\right.$-tri- $\mu H$-nido-decaborano(14)]-6', $7^{\prime}$ dicommo-5,6-[6,7:8,9:9,10-tri- $\mu H$-nido-decaborane(14)], for the isomer commonly referred to as $n$ - $\mathrm{B}_{18} \mathrm{H}_{22}$ (or anti- $\left.\mathrm{B}_{18} \mathrm{H}_{22}\right)\left(25 \mathrm{~A}\right.$ and 25B), and $\left[6^{\prime}, 7^{\prime}: 8^{\prime}, 9^{\prime}: 9^{\prime}, 10^{\prime}\right.$-tri- $\mu \mathrm{H}$-nido-decaborano(14)]-5',6'-dicommo-5,6-[6,7:8,9:9,10tri- $\mu \mathrm{H}$-nido-decaborane(14)], for the isomer commonly referred to as iso- $\mathrm{B}_{18} \mathrm{H}_{22}$ (or $\left.s y n-\mathrm{B}_{18} \mathrm{H}_{22}\right)(\mathbf{2 6} \mathrm{A}$ and 26B). It should be noted that syn- $\mathrm{B}_{18} \mathrm{H}_{22}$, (26), is chiral and the other enantiomer would have the name $\left[5^{\prime}, 6^{\prime}: 8^{\prime}, 9^{\prime}: 9^{\prime}, 10^{\prime}\right.$-tri- $\mu H$-nido-decaborano(14)]-6', $7^{\prime}$-dicommo-6,7-[5,6:8,9:9,10-tri- $\mu H$-nido-decaborane(14)]. Although in principle these compounds could also be named as under a system developed in organic chemistry for chiral fullerenes (see Section Fu-17, [7]), no formal recommendations on the topic are made here. See also the related discussion on 5-Cl-nido- $\mathrm{B}_{10} \mathrm{H}_{13}$ in Section BN-4.1. Structures 25A and 26A have common vertices that do not possess terminal hydrogen atoms, these vertices are signified by black dots.

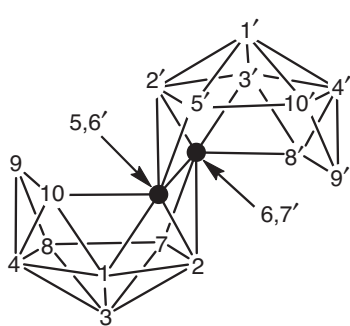

25A

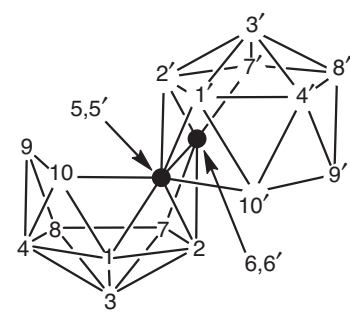

26A
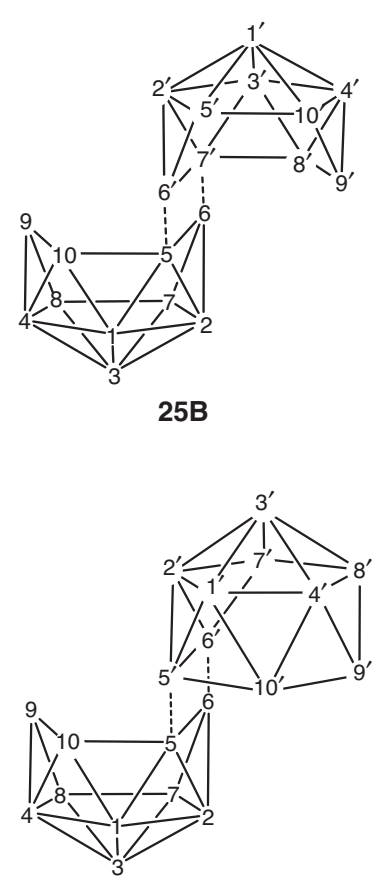

26B

Here the trivial descriptors syn and anti refer to the mutual disposition of the two nido-decaborane open faces, either on the same flank (syn) or on opposite flanks (anti) of the molecule. These mutual dispositions have been further categorised as 'transoid', implying that the open faces are trans to each other, engendering trivial transoid-anti and transoid-syn descriptors for these two known isomers [18]. The alternative 'cisoid' 
conjunctions, with the open faces cis to each other, have not yet been realised experimentally. However, such 'cisoid' conjunctions have been proposed to be inherently isolatable.

There are cases where, in addition to the two-atoms-in-common fusion, the two subcages are conjoined with a $\sigma$-link, or by a one-atom bridge. Organic nomenclature provides a system to describe the additional $\sigma$-link: the prefix 'cyclo' (not italicised) in front of the fused borane cages as $x, y^{\prime}$ cyclo-[borano]- $a^{\prime}, b^{\prime}$-dicommo-c, $d$-[borane]. Systems with bridging ligands may be similarly cited as $x, y^{\prime}$ - $\mu$-bridge-[borano]- $a^{\prime}, b^{\prime}$-dicommo-c, $d$-[borane], e.g. the $\mathrm{S}_{2} \mathrm{~B}_{16} \mathrm{H}_{16}$ species (27) can be named 3,5', $6^{\prime}-\mu_{3}-$ sulfido[4', $5^{\prime}: 6^{\prime}, 7^{\prime}$-di- $\mu H$-nido-octaborano(8)]-8', $3^{\prime}$-dicommo-7,8-[10,11- $\mu$ H-nido-9-thiaundecaborane(10)].

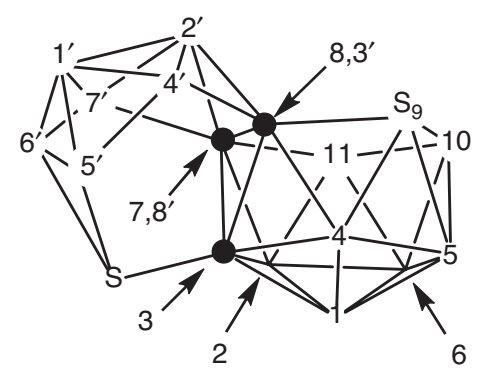

27

This dicommo system is generally applicable when the two subcages are recognisable in terms of known types of single cages. However, there are one or two problem compounds and it is likely that more of these will be revealed as the area progresses. By a two-atoms-conjoined formalisation, and by hydrogen-atom count, the compound $\mathrm{B}_{14} \mathrm{H}_{20}$ would in principle be a dicommo nido-eight-vertex/arachno-eight-vertex combination. However, this would be asymmetric, whereas the overall structure and hydrogen-atom disposition are symmetrical. The overall formulation is $\mathrm{B}_{n} \mathrm{H}_{n+6}$, and electron counting rules [5] would suggest a single-cage arachno, but to regard it as a fourteen-vertex fragment of a sixteen-vertex closo polyhedron is geometrically unrealistic. At present the species is unique and more examples of this general type would have to be isolated before a general structural pattern emerges and the basis for a systematic nomenclature perceived. The numbering scheme historically applied to $\mathrm{B}_{14} \mathrm{H}_{20}$ is as in $\mathbf{2 8}$ [19]. A related problem exists with $\mathrm{B}_{12} \mathrm{H}_{16}$ although this can at least be described structurally as a dicommo combination of a nido-shaped eight-vertex cage and a nido-shaped six-vertex cage, but precise bridging hydrogen-atom locations would have to be specified.

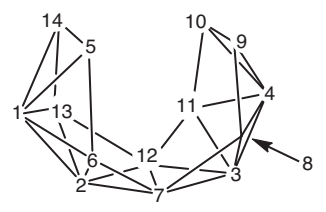

28

As a logical extension of the dicommo approach, it is recommended that tricommo nomenclature is used, e.g. [borano]- $a^{\prime}, b^{\prime}, c^{\prime}$-tricommo- $x, y, z$-[borane] is appropriate for cage compounds that can be interpreted in terms of recognizable single cages fused with three atoms in common (face fusion) (Recommendation 18). This can be applied to several known compounds, but in some cases constituent cage types may become difficult to define in terms of known and definable single cage shapes, particularly so as the intercage fusion becomes more intimate.

Really intimate intercage fusion can in principle result in larger 'globular' boranes [20, 21] and related assemblies that have been called 'stuffed cages' [22]. The latter are non-hollow cages (cages with atoms inside) which are not recognisable in terms of individual single-cage components and for which it is not practicable to devise a systematic nomenclature until several experimentally determined examples are known and systematic structural patterns emerge. At the time of this report, only very hypothetical species, such as $\mathrm{B}_{27} \mathrm{H}_{21}$ and $\mathrm{B}_{84} \mathrm{H}_{54}$, have been proposed based on speculative calculations [20-22], but perhaps future nomenclature in this area can utilise variants on organic diamondoid or endo-fullerene “@” nomenclature and numbering 
conventions. A unique species that should be mentioned in this context is $\mathrm{B}_{20} \mathrm{H}_{16}$, a long-known compound commonly named closo- $\mathrm{B}_{20} \mathrm{H}_{16}$ on account of its closed deltahedral constitution. However, the structure is not that of a deltahedral cage, as typified by the conventional closo- $\left[\mathrm{B}_{n} \mathrm{H}_{n}\right]^{2-}$ structural sequence, but has a more columnar aspect, and so the use of 'closo' in terms of systematic nomenclature is inappropriate. Calculations suggest that $\mathrm{B}_{20} \mathrm{H}_{16}$ is in fact part of a structural and electronic progression based on dianionic closo- $\left[\mathrm{B}_{n} \mathrm{H}_{n}\right]^{2-}$, neutral $\mathrm{B}_{20} \mathrm{H}_{16}$, dicationic $\left[\mathrm{B}_{28} \mathrm{H}_{20}\right]^{2+}$, tetracationic $\left[\mathrm{B}_{34} \mathrm{H}_{24}\right]^{4+}$, and so on, of which $\mathrm{B}_{20} \mathrm{H}_{16}$ and $\left[\mathrm{B}_{28} \mathrm{H}_{20}\right]^{2+}$ would constitute initial members of a series of columnar structures, for which the prefix columno is appropriate. $\mathrm{B}_{20} \mathrm{H}_{16}$ would thence be columno-2,2,4,2,2,4,2,2- $\mathrm{B}_{20} \mathrm{H}_{16}$, the numbers representing the numbers of atoms in successive planes as the column is descended, this sequence being consistent with the previously described historical numbering system for this compound, as in Section 11.11 of the 1970 recommendations [4d]. Alternatively, such structures could be named by the descriptors described in Section BN-7.2 using Recommendation 19.

\section{BN-7.2 Supra-icosahedral structures}

\section{BN-7.2.1 Introduction}

Recommendation 19: A new system for the description of closed (closo) supra-icosahedral polyhedral shapes based on a published method [23] is recommended. Closed (closo) 13- to 16-vertex polyhedra are shown in Fig. 3. In this system the overall idealized symmetry, the number of atoms in the cage within 'planes', their connectivities, and the number of triangulated faces may all be defined (Fig. 3). Numbering, except for those described in Recommendations 20 and 21, follows the clockwise-in-planes rules, as is current practice in subicosahedral cages, as defined in IUPAC Recommendations 1990 [2f].

Currently there are no IUPAC recommendations for the naming of 'supra-icosahedral' boron hydrides (i.e. those with more than twelve cage vertices) or related species. Although theoreticians have long predicted supra-icosahedral boranes, metallaboranes, and heteroboranes, the area is still very much under-developed from a synthetic viewpoint. However, progress in synthetic methods in recent years indicates that it is now time to review this area. Closed (closo) structures are examined first and this will be followed by a discussion on open (nido or arachno) structures.

Theoretical calculations have been undertaken on deltahedral closed $\left[\mathrm{B}_{n} \mathrm{H}_{n}\right]^{2-}$ systems where $n$ has taken the value between 13 and 24, inclusive [24]. In keeping with sub-icosahedral closed cages, these structures all contain exo hydrido substituents. They all possess 12 vertices with a cage-connectivity of five, and $n-12$ vertices with a cage-connectivity of six. Continuation of the systematic nomenclature for sub-icosahedral structures would indicate that these should be correctly named as closo structures, and that nido and arachno structures could be derived from them using conventional vertex-subtraction rules. However, in light of synthetic work, it is clear that structural aspects of supra-icosahedral cages are more complex than for the smaller sub-icosahedral cages and it is (at present) difficult to make any generalizations about what particular shapes may form the basis of a rigorous nomenclature. Thus, it has been shown that closed polyhedral shapes other than those $[24,25]$ historically calculated for $\left[\mathrm{B}_{n} \mathrm{H}_{n}\right]^{2-}$ are also available, and a more all-encompassing approach to nomenclature needs to be developed.

Supra-icosahedral $\left[\mathrm{B}_{n} \mathrm{H}_{n}\right]^{2-}$ cages have not (yet) been synthesized, but there are now known examples of 13-vertex and 14-vertex carbaboranes; 13-, 14-, and 15-vertex metallacarbaboranes; and 15-vertex and 16-vertex metallaboranes [26-29].

\section{BN-7.2.2 Closed 13-vertex cages}

Recommendation 20: The non-standard numbering for henicosahedral 13-vertex species (Fig. 3) species is well entrenched in the literature, and their continued use is recommended. 


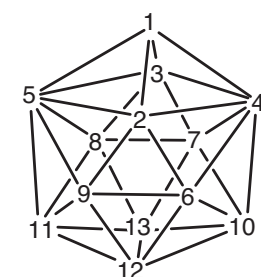

13-vertex $\left[C_{2 v}-\left(1 v^{4} 22 v^{6} 422\right)-\Delta^{22}-\right.$ closo $]$

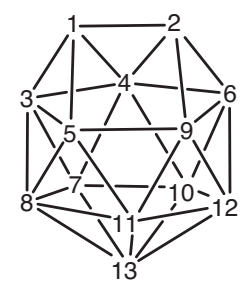

13-vertex*

$\left[C_{\mathrm{s}}-\left(2 v^{4} 551\right)-\Delta^{20}-\right.$ closo $]$

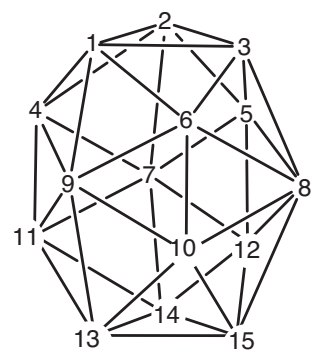

15-vertex

$\left[D_{3 \mathrm{~h}}-\left(333 v^{6} 33\right)-\Delta^{26}-\right.$ closo $]$
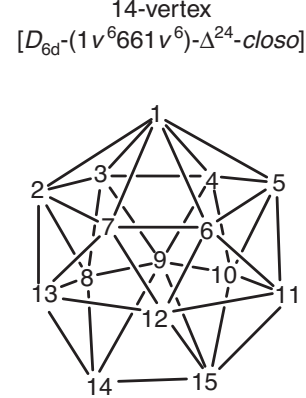

15-vertex *

$\left[C_{\mathrm{s}}-\left(1 v^{6} 662\right)-\Delta^{24}-\right.$ closo $]$

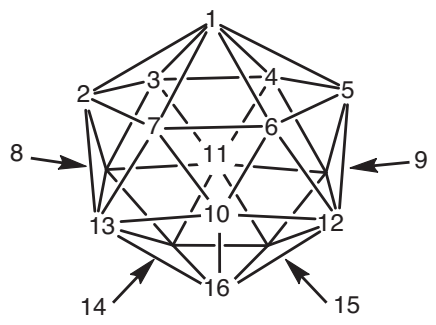

16-vertex

$\left[T_{d}-\left(1 v^{6} 633 v^{6} 3\right)-\Delta^{28}-\right.$ closo $]$

Fig. 3: Supra-icosahedral closo 13-16 vertex structures with associated numbering schemes. The numbering schemes for 13and 14-vertex species are well entrenched in the literature. 15- and 16-vertex structures follow conventional clockwise in planes numbering. The 13-vertex $\left[C_{s}-(2551)-\Delta^{20}\right.$-closo $]$ and 15 -vertex $\left[C_{s}-(1662)-\Delta^{24}\right.$-closo $]$ contain quadrilateral faces and are nido-like but are named closo. Non-standard numbering denoted by *.

There are many known examples of closed 13-vertex $\left\{\mathrm{MC}_{2} \mathrm{~B}_{10}\right\}$ cage compounds, in which the cages adopt the deltahedral structure with 22 faces (docosahedron), isostructural with that calculated for $\left[\mathrm{B}_{13} \mathrm{H}_{13}\right]^{2-}$. Recent calculations have suggested that structures of supra-icosahedral closo carbaboranes and metallacarbaboranes need not be fully deltahedral and that 'tubular' or other polyhedral shapes might be possible [30]. 13-Vertex $\left\{\mathrm{C}_{2} \mathrm{~B}_{11}\right\}$ carbaboranes, e.g. 1,2- $\mu-\left[1^{\prime}, 2^{\prime}-\mathrm{C}_{6} \mathrm{H}_{4}\left(\mathrm{CH}_{2}\right)_{2}\right]-3-\mathrm{Ph}-$ closo- $1,2-\mathrm{C}_{2} \mathrm{~B}_{11} \mathrm{H}_{10}$, have a non-deltahedral henicosahedral (21 faces) structure, with twenty triangulated faces and one trapezoidal $\left(\mathrm{C}_{2} \mathrm{~B}_{2}\right)$ face [31]. This alternative closed structure needs to be differentiated from the docosahedral closed structure. This could easily be accomplished by adopting a system first described by Powell and co-workers [23]. This system includes both the number of cage atoms found within the 'planes', and the number of triangulated faces, within the structural descriptor. Other additional qualifying descriptors, such as an idealized symmetry point group symbol, and the cage-atom connectivity $\left(v^{n}\right)$, may also be included, if necessary. For example, for the 10-vertex bicapped square antiprismatic polyhedron (hexadecahedron) the descriptor would be $\left[D_{4 \mathrm{~d}}-\left(1 v^{4} 441 v^{4}\right)-\Delta^{16}-\operatorname{closo}\right]$ (the ' $v^{5}$, descriptor for the 5 -vertex middle numbers is implicit and has been omitted). For this manuscript the point group, the number of faces given in the superscript number to the $\Delta$ symbol, and the descriptor e.g. closo are generally included in the structural descriptor contained in square brackets (Recommendation 19). 
Numbering systems in both henicosahedral and docosahedral structures are in common usage in the literature and it is recommended that these be formally adopted (Recommendations 19 and 20) [32]. Both structures, together with their accepted numbering patterns, are shown in Fig. 3.

Thus, 1,2- $\mu-\left[\mathrm{CH}_{2}\right]_{3}-3-\mathrm{Ph}$-closo-1,2- $\mathrm{C}_{2} \mathrm{~B}_{11} \mathrm{H}_{10}$ (29) with a henicosahedral structure may be named 3-phenyl-1,2(propane-1,3-diyl) $\left[C_{s}-\left(2 v^{4} 551\right)-\Delta^{20}\right.$-closo]-1,2-dicarbatridecaborane(13). It should be noted that this is an ad hocsolution that would not work for an unsymmetrical bridging group, e.g. propane-1,2-diyl. This points to a need for a system for names for polyvalent substituent groups similar to the kappa system [1c, 1d] for ligand names, i.e. where the bridging sites (in casu the atoms of the cage) can be specified individually for the various free valences. This will be the subject of further studies.

The anions with a docosahedral structure, $\left[\mathrm{B}_{13} \mathrm{H}_{13}\right]^{2-}$ and the 'carbon atoms apart' metallacarbaborane $\left[4,4,4-(\mathrm{CO})_{3}-1,6,4-\mathrm{C}_{2} \mathrm{ReB}_{10} \mathrm{H}_{12}\right]^{-}$, are named tridecahydrido $\left[\mathrm{C}_{2 \mathrm{v}}-\left(1 v^{4} 22 v^{6} 422\right)-\Delta^{22}-\right.$ closo $]$ tridecaborate $(2-)$ and 4,4,4-tri(carbonyl)dodecahydrido $\left[C_{2 v}-\left(1 v^{4} 22 v^{6} 422\right)-\Delta^{22}-\right.$ closo $]-1,6$-dicarba-4-rhenatridecaborate(1-), respectively.

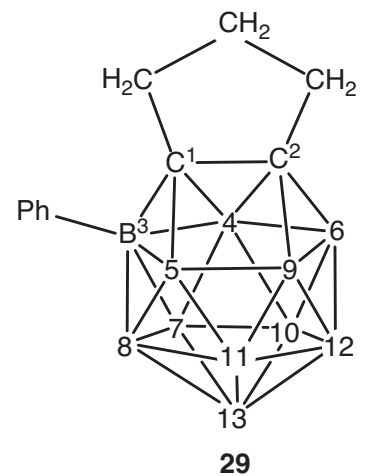

\section{BN-7.2.3 Closed 14-vertex cages}

The deltahedral structure calculated for the closo 14-vertex cage is the bicapped hexagonal- antiprismatic tetracosahedron with 24 deltahedral faces and $D_{6 \mathrm{~d}}$ symmetry (see Fig. 3). This structure has two BH units occupying the two cage six-connected vertices. It is recommended that the generally accepted numbering system for these tetracosahedral cages be adopted (Recommendation 19, Fig. 3) [33]. The tetracosahedron has the Powell [23] descriptor $\left[D_{6 \mathrm{~d}}-\left(1 v^{6} 661 v^{6}\right)-\Delta^{24}\right.$-closo $]$. The largest known heteroborane to date, 2,3- $\mu-\left[\mathrm{CH}_{2}\right]_{3}-$ closo2,3- $\mathrm{C}_{2} \mathrm{~B}_{12} \mathrm{H}_{12}$ [27], has this structure, and can be named by bridging nomenclature as 2,3-(propane-1,3-diyl) $\left[D_{6 \mathrm{~d}}-\left(1 v^{6} 661 v^{6}\right)-\Delta^{24}\right.$-closo $]$-2,3-dicarbatetradecaborane(14).

Closed isostructural 14-vertex $\left\{\mathrm{C}_{2} \mathrm{M}_{2} \mathrm{~B}_{10}\right\}$ and $\left\{\mathrm{C}_{4} \mathrm{M}_{2} \mathrm{~B}_{8}\right\}$ systems are known e.g. 1,14- $\left(\eta^{5}-\mathrm{C}_{5} \mathrm{H}_{5}\right)_{2}$-closo-2, $10,1,14-\mathrm{C}_{2} \mathrm{Co}_{2} \mathrm{~B}_{10} \mathrm{H}_{12} \quad$ (30), which is named 1,14-bis $\left(\eta^{5}\right.$-cyclopentadienido $)\left[D_{6 \mathrm{~d}}-\left(1 v^{6} 661 v^{6}\right)-\Delta^{24}\right.$-closo -2 , 10-dicarba-1,14-dicobaltatetradecaborane(12).

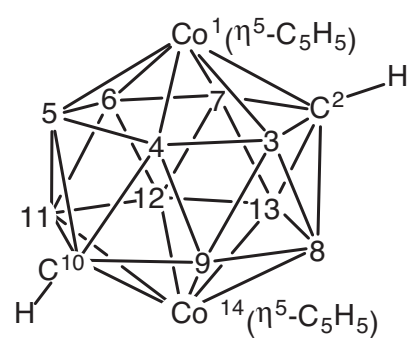




\section{BN-7.2.4 Closed 15-vertex cages}

Recommendation 21: The non-standard numbering for pentacosahedral 15-vertex (Fig. 3) species is well entrenched in the literature, and its continued use is recommended.

The calculated deltahedral structure for the 15 -vertex $\left[\mathrm{B}_{15} \mathrm{H}_{15}\right]^{2-}$ is the hexacosahedron (26 faces) with $D_{3 \mathrm{~h}}$ symmetry. This structure has been observed in species such as $\left(\eta^{5}-\mathrm{C}_{5} \mathrm{Me}_{5} \mathrm{Rh}\right)_{2} \mathrm{~B}_{13} \mathrm{H}_{13}$ [28], and 1,4- $\mu-\left[\mathrm{CH}_{2}\right]_{3}-7-\left(\eta^{6}-1-\right.$ isopropyl-4-methylbenzene)-1,4,7- $\mathrm{C}_{2} \mathrm{RuB}_{12} \mathrm{H}_{12}$ [34], and the cage structure corresponds to a Powell descriptor [23] of $\left[D_{3 \mathrm{~h}}-\left(333 v^{6} 33\right)-\Delta^{26}-\right.$ closo]. The numbering scheme for these closo structures is shown in Fig. 3 and ( $\eta^{5-}$ $\left.\mathrm{C}_{5} \mathrm{Me}_{5} \mathrm{Rh}\right){ }_{2} \mathrm{~B}_{13} \mathrm{H}_{13}(31)$, where $\mathrm{M}=\left[\mathrm{Rh}\left(\eta^{5}-\mathrm{C}_{5} \mathrm{Me}_{5}\right)\right]$, is correctlynamedas 7,8-bis $\left(\eta^{5}\right.$-pentamethylcyclopentadienido $)$ $\left[D_{3 \mathrm{~h}}-\left(333 v^{6} 33\right)-\Delta^{26}\right.$-closo]-7,8-dirhodapentadecaborane(13) (Recommendation 19).

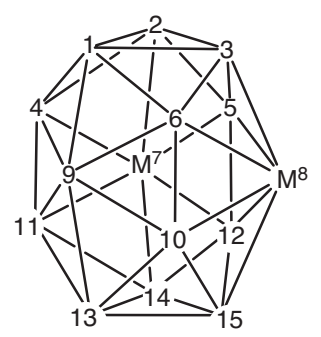

31

A second compound with a closo 15-vertex cage, 1-( $\eta^{6}-1$-isopropyl-4-methylbenzene)-8,14- $\mu-\left[\mathrm{CH}_{2}\right]_{3}-8,14,1-$ $\mathrm{C}_{2} \mathrm{RuB}_{12} \mathrm{H}_{12}$, isomeric to that just mentioned, has a pentacosahedral (25-face) solid-state cage structure. This structure (see Fig. 3) has a quadrilateral face and 24 triangulated faces. In solution it has effective mirrorplane symmetry $\left(C_{s}\right)$ with a similar $\left(1 v^{6} 662\right)$ plane arrangement, and is numbered accordingly (Fig. 3$)$. It is recommended that this numbering scheme be retained for these closo pentacosahedral 15-vertex systems (Recommendation 21) [35].

\section{BN-7.2.5 Closed 16-vertex cages}

The calculated deltahedral structure for the 16-vertex closo- $\left[\mathrm{B}_{16} \mathrm{H}_{16}\right]^{2-}$ structure is an octacosahedron (28 faces) with $T_{\mathrm{d}}$ symmetry. This structure has been observed in a recently reported closed metallaborane cage containing a $\left\{\mathrm{Rh}_{4} \mathrm{~B}_{12}\right\}$ core [29] with a Powell descriptor [23] of $\left[T_{\mathrm{d}}-\left(1 v^{6} 633 v^{6} 3\right)-\Delta^{28}\right.$-closo]. This is shown in Fig. 3 together with the vertex numbering scheme (Recommendation 19). The compound containing this cage has a rhodium atom that is held in common with a closo 16-vertex and a nido six-vertex cage and the compound is a good example to illustrate the recommendations associated with conjoined (Recommendation 18) and supra-icosahedral (Recommendation 19) nomenclature. Thus, 32 (where $\mathrm{M}=\left[\mathrm{Rh}\left(\eta^{5}-\mathrm{C}_{5} \mathrm{Me}_{5}\right)\right]$ ) is correctly named $1^{\prime}, 11,12,13$-tetrakis(pentamethylcyclopentadienido) $\left[2^{\prime}, 3^{\prime}: 2^{\prime}, 6^{\prime}: 3^{\prime}, 4^{\prime}: 4^{\prime}, 5^{\prime}: 5^{\prime}, 6^{\prime}\right.$-penta- $\mu H$-nido-1,2-dirhodahexaborane(9)]-2' - commo-1-[[ $T_{\mathrm{d}}-\left(1 v^{6} 633 v^{6} 3\right)-\Delta^{28}$ closo]-1,11,12,13-tetrarhodahexadecaborane(12)].

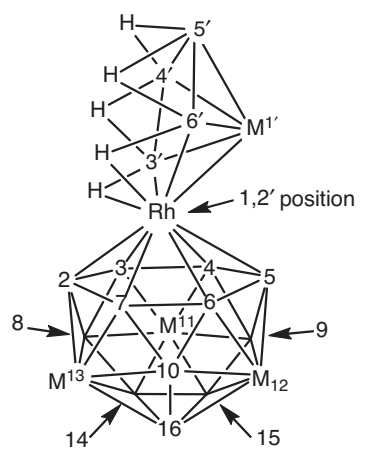




\section{BN-7.2.6 Open supra-icosahedral cages}

Recommendation 22: The 'debor' method [2p, 36] is recommended for naming open supra-icosahedral species.

Open (i.e. nido- or arachno-type) structures have been reported for cages with 12-14 vertices that are based on closed supra-icosahedral polyhedra of 13-15 vertices with one or two vertices removed [26]. Open structures based on closo polyhedra with $>15$ vertices have not yet been synthesized and are not considered further in this report.

It is expected that nido 12-vertex structures are based on the closed 13-vertex shapes, with the highestconnected vertex removed. The nido- $\left[7,9-\mathrm{C}_{2} \mathrm{~B}_{10} \mathrm{H}_{12}\right]^{2-}$ anion and the neutral molecule nido- $\mathrm{Et}_{4} \mathrm{C}_{4} \mathrm{~B}_{8} \mathrm{H}_{8}$ have a geometry based on the docosahedral closo structure. This nido 12-vertex structure, together with alternative nido structures that have been observed, are shown in Fig. 4. Synthesized nido 13-vertex and arachno 12-vertex cages are structurally derived from the closo 14-vertex tetracosahedral cage (bicapped hexagonal antiprism), with one or two vertices missing, respectively. There are three different cage types reported for arachno-type 12-vertex systems. These structures are illustrated in Fig. 4, and their shapes have been described as 'hexagonal antiprismatic', 'basket-shaped', and 'carbons adjacent with two open faces' [26]. The 'hexagonal antiprismatic' structure is related to the expected 14-vertex $\left[D_{6 \mathrm{~d}}-\left(1 v^{6} 661 v^{6}\right)-\Delta^{24}-c l o s o\right]$ structure, but the two vertices removed are both of cage-connectivity six and mutually antipodal, rather than adjacent as is conventionally proposed for the generation of arachno structures. Similar examples in sub-icosahedral systems have been

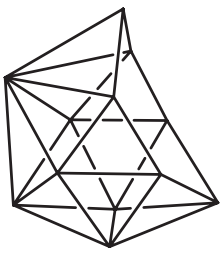

nido 12-vertex remove a sixconnected vertex

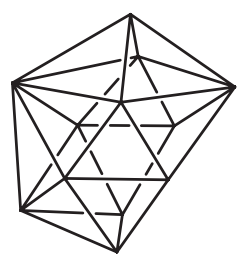

nido12-vertex remove a fiveconnected vertex
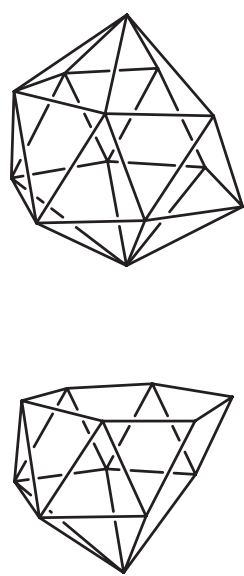

arachno 12-vertex remove non-adjacent sixand five-connected vertices 'carbon atoms adjacent with two open faces'

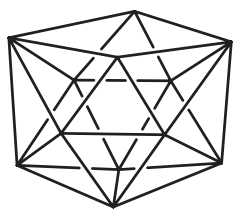

nido 12-vertex remove a fourconnected vertex (isonido)

nido 13-

vertex

remove

five-

connected

vertex

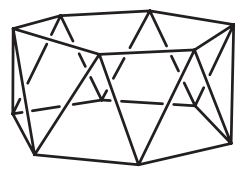

arachno 12-vertex remove two six-connected antipodals

'hexagonal antiprismatic'

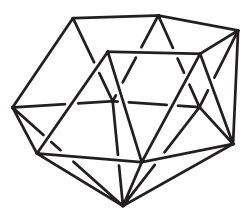

arachno 12-vertex-type remove adjacent six- and fiveconnected vertices 'basket'

Fig. 4: 12-vertex, nido and arachno and 13-vertex nido supra-icosahedral structures and relationships to higher closo geometries, shown in Fig. 3. 
referred to as 'remote' arachno (see Section BN-7.3, also schematic cage structure 2), although this is not an IUPAC-accepted term. Structurally, it could trivially be interpreted as a 'bis-nido' species, rather than the more open arachno cage. This may be a case where the electron count is the origin of the literature name rather than the observed structure, although, as recommended elsewhere in this document, structural nomenclature should be based on observed structure rather than perceived electronic considerations, which may often be subjective. The 'carbon atoms adjacent with two open faces' isomer is again derived from the deltahedral 14-vertex $\left[D_{6 \mathrm{~d}}\left(1 v^{6} 661 v^{6}\right)-\Delta^{24}\right.$-closo $]$ structure, but this time with the six-connected and a five-connected cage atom (from the lower belt, rather than the conventionally specified adjacent belt) removed. Again, this might be trivially viewed as a 'bis-nido' species rather than the more open arachno cage. The nido 13-vertex cage compound [Ni(dppe) $\left.\left(\mathrm{Me}_{4} \mathrm{C}_{4} \mathrm{~B}_{8} \mathrm{H}_{8}\right)\right]\left(\mathrm{dppe}=\mathrm{Ph}_{2} \mathrm{PCH}_{2} \mathrm{CH}_{2} \mathrm{PPh}_{2}\right)$, which is also based on the expected bicapped hexagonal antiprism, has a 5-connected cage vertex removed, rather than the highest-connectivity 6-connected cage vertex. This structure is also illustrated in Fig. 4.

The significant structural variations described in the last paragraph emphasize the need for a robust nomenclature system for such open cages. The 'debor' method [2p, 36] for describing open cages is part of IUPAC Recommendations for the naming of open cages. This 'debor' method, combined with Powell descriptors [23] available for the related closo species from which the open structures are derived, is the preferred method of naming such open supra-icosahedral structures (Recommendation 22). In essence, the compound is named with the prefix $x$-debor, $x, y$-didebor, or $x, y, z$,-tridebor (where $x, y$ and $z$ are locants), followed by the name of the closed structure ending with 'ane' (for a neutral borane) and the actual number of hydrogen atoms (in the unsubstituted open-cage parent) in parenthesis. Names of negatively charged species would need to specify hydrido positions, end with 'ate', and have the charge in parentheses.

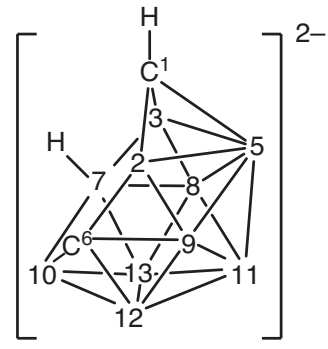

33

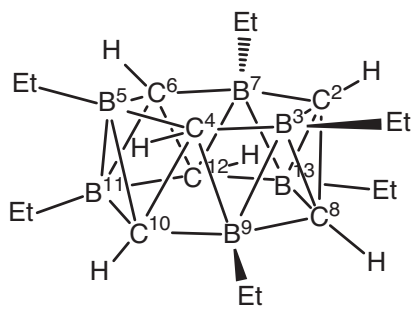

34

Examples of nomenclature using the 'debor' method [2p, 36] are dodecahydrido-4-debor[ $C_{2 v}-\left(1 v^{4} 22 v^{6} 422\right)$ $\Delta^{22}$-closo]-1,7-dicarbatridecaborate(2-) for 33 and 3,5,7,9,11,13-hexaethyl-1,14-didebor[ $\left[D_{6 \mathrm{~d}}-\left(1 v^{6} 661 v^{6}\right)\right.$ - $\Delta^{24}$-closo]2,4,6,8,10,12-hexacarbatetradecaborane(12) for 34. Here, the ' $x$-debor-' term is considered as part of the descriptor and immediately precedes it.

Overall, as more extensive supra-icosahedral chemistry is evolved, these recommendations may have to be revisited.

\section{BN-7.3 Non-conventional deltahedral structures}

Recommendation 23: The structural terms isocloso and isonido are recommended for nine-, ten-, and twelve-vertex species, including their historical numbering schemes (Fig. 5). Within eleven-vertex species, the isonido descriptor, with its associated numbering based on the closo eleven-vertex scheme (Fig. 1), is also recommended (Fig. 5).

Recommendation 24: Closed geometries derived from polyhedra that are not within the conventional deltahedral set shown in Fig. 1 should be described by descriptors based on the principles [2f, 23] recommended for supra-icosahedral cages (Recommendation 19). 


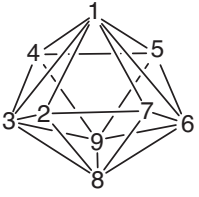

isocloso 9-vertex 1:4:2:2 stack

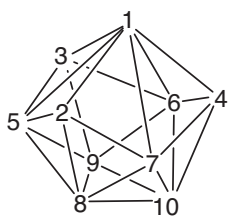

isocloso 10-vertex 1:3:3:3 stack

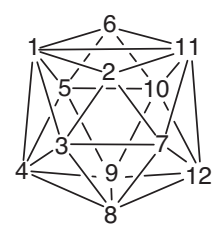

isocloso 12-vertex 2:2:4:2:2 stack

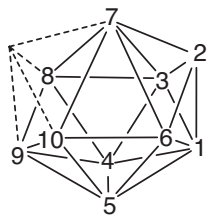

isonido 10-vertex from closo 11-vertex
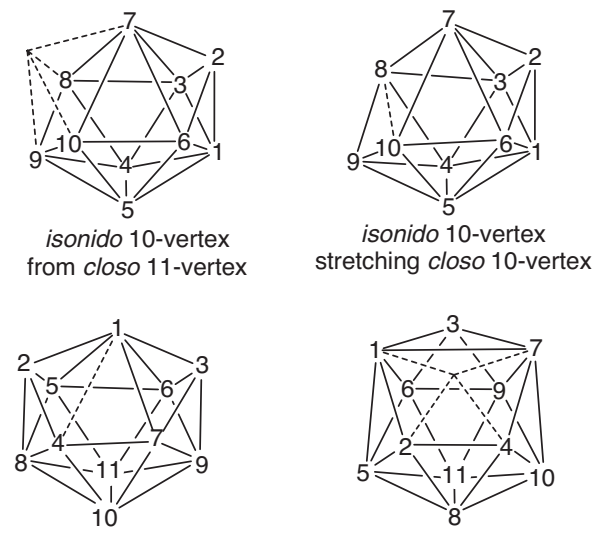

isonido 11-vertex stretching closo 11-vertex

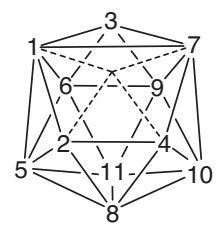

isonido 11-vertex from isocloso 12-vertex

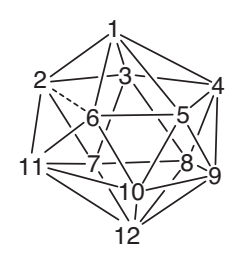

isonido 12-vertex stretching closo 12-vertex

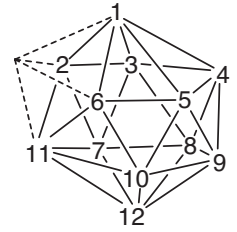

isonido 12-vertex from closo 13-vertex

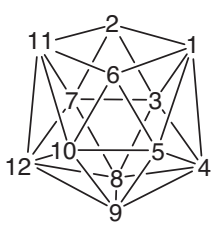

isonido 12-vertex 2:2:4:2:2 stack

Fig. 5: 9-, 10- and 12-vertex isocloso and ten-, eleven- and twelve-vertex isonido cage geometries with their associated numbering schemes. Although the twelve-vertex isonido and isocloso structures have their own idealized two-fold symmetries with a 2:2:4:2:2 stack structure, they are numbered by custom and practice as for conventional closo. The isonido eleven-vertex geometry also has an idealized two-fold symmetry, with a 1:2:2:2:2:2 stack structure, but by custom and practice is numbered as for conventional closo.

Recommendation 25: The 'debor' method [2p, 36] is recommended for 'non-standard' open structures other than those highlighted in Recommendation 23.

Terms such as pseudocloso, quasicloso, hypercloso, precloso, oblato, isocloso, isonido and isoarachno have also been used for the naming of cages, although they are not IUPAC recommended terms. These are discussed below. The situation is rapidly becoming confusing and unsystematic, as such terms are often introduced by authors to explain subtle structural and electronic nuances. However, it is recommended that structural descriptors in nomenclature be based solely on the observed (idealized) structure.

The majority of known sub-icosahedral boron-hydride and boron-hydride-related species have cage geometries that have idealized structures adequately described by the structural descriptors closo, nido, and arachno, based on conventional deltahedral shapes (Figs. 1 and 2; Section BN-3). The inclusion of the qualification 'idealized' indicates that not all interatomic distances and angles in subrogated boron hydrides are identical to those observed in the symmetrical parent model systems and due allowance must be made for this. Thus, for example, twelve-vertex metallacarbaborane derivatives such as [3- $\left(\eta^{5}-\mathrm{C}_{5} \mathrm{Me}_{5}\right)$-closo-1,2,3$\left.\mathrm{C}_{2} \mathrm{IrB}_{9} \mathrm{H}_{11}\right]$ are clearly based on the closed deltahedral icosahedron, despite Ir-B and Ir-C interatomic distances being longer than the B-B distances observed in $\left[\mathrm{B}_{12} \mathrm{H}_{12}\right]^{2-}$ and $\mathrm{C}-\mathrm{C}$ distances being shorter. There will also 
be variations among the B-B distances. Such deviations from the ideal result primarily from changing atom (orbital) size and from antipodal and other directional effects within the cage. Nevertheless, the connectivities of the cage atoms and the idealized cage symmetries clearly warrant the use of the term closo.

Closed eleven-vertex systems, such as 2,3- $\mathrm{C}_{2} \mathrm{~B}_{9} \mathrm{H}_{11},\left[2-\mathrm{CB}_{10} \mathrm{H}_{11}\right]^{-}$, and $\left[\mathrm{B}_{11} \mathrm{H}_{11}\right]^{2-}$, have historically been named closo and assigned the octadecahedral structure shown in Fig. 1. This structure has long interatomic distances between the boron atom at cage position 1 of formal cage-connectivity six and four of its neighbours in the 4 , 5, 6, and 7 sites. Recent evidence, e.g. structural data (measured or calculated interatomic distances), chemical behaviour, and, in some cases, fluxional behavior in solution, has been taken to indicate that they do not necessarily possess a formal closed deltahedral structure but the four long connectivities are essentially nonbonding, so that the species have effectively two five-membered open faces reminiscent of a 'remote arachno' configuration (e.g. 35A and 35B) [37]. The term quasiclosohas been coined for such structures. However, in essence they generally show (often time-averaged) connectivities of the closed eleven-vertex hexadecahedron $\left(C_{2 v}\right)$. It is therefore recommended that the term closo, with its associated numbering system, be used (Recommendation 23) for such structures and that the term quasiclosois not acceptable. Nevertheless, if an observed structure clearly has an open face (e.g. as determined by $X$-ray diffraction studies) then it should be named as such (nido or isonido). The term isocloso has also been used in certain compounds for the elevenvertex closo structure, but such a description is based on perceived electronic structure rather than observed geometrical structure and for nomenclature this practice is not acceptable (see below).

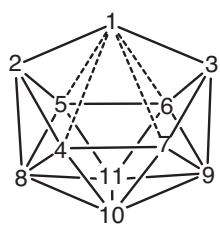

$35 \mathrm{~A}$

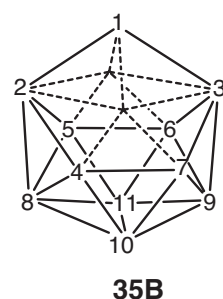

35B

Isocloso, isonido, and isoarachno have been used to describe sub-icosahedral cages with non-standard connectivities or geometries. These may be based on unexpected closed polyhedra or have open structures based on conventional closed structures but with unusual (i.e. not highest- connected or non-adjacent) vertices removed. From a historical and structural point of view, these terms have some merit in nomenclature provided they are not associated with electron-counting schemes. In practice, these alternative geometries have been limited to nine-, ten-, eleven- (see above for isocloso), and twelve-vertex species and it is recommended that the geometries shown in Fig. 5 (and their associated numbering schemes) are retained (Recommendation 23). The isonido compound 7,7,9-( $\mathrm{PPh})_{3}$-isonido-7-- $\mathrm{IrB}_{9} \mathrm{H}_{10}$ has an exo $\mathrm{B}-\mathrm{H}$ hydrogen atom replaced by the neutral substituent $\mathrm{PPh}_{3}$. This cage therefore needs to be named by the located hydrogen method (see Section BN-4.1) as 7,7,9-tris(triphenylphosphane-P)-9-dehydro-7:8,9:10-di- $\mu H$-isonido-7-iridadecaborane(11) (36).

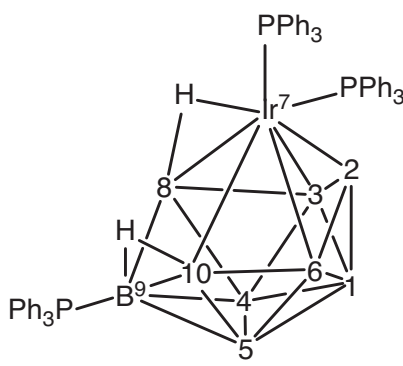

36

Using the 'debor' method [2p, 36] the isonido structure, 7,7,9-( $\left.\mathrm{PPh}_{3}\right)_{3}$-isonido-7- $\mathrm{IrB}_{9} \mathrm{H}_{10}(36)$ could equally be named as 1,1,8-tris(triphenylphosphane- $P$ )-8-dehydro-2-debor-1,5:4,8-di- $\mu H$ - $\left[C_{2 \mathrm{v}}\right.$-(12422)- ${ }^{18}$-closo]-1- 
iridaundecaborane(11), based on the closo structure as numbered in Fig. 1, or 35A. The 'debor' prefix is part of the cage name, as are the 'indicated hydrogens'. The 'dehydro' prefix should precede the cage as an un-alphabetised detachable prefix. Should the need arise for new 'iso' structures, then the use of the 'planes' method [2f], for closo structures, and the 'debor' nomenclature [2p, 36], for open structures (Recommendations 24 and 25), as described in detail in the supra-icosahedral Section BN-7.2 should be used. This would also be an acceptable alternative nomenclature system for these nine- and ten-vertex isonido and isocloso systems. The isocloso ten-vertex system (Fig. 5) could also be further defined as $\left[C_{3 v}-\left(1 v^{6} 333\right)\right.$ $\Delta^{16}$-closo] if required.

Pseudocloso has been used as a descriptor for some twelve-vertex formally closed cages that contain some interatomic distances that are longer than expected. This is often held to be the result of severe steric congestion arising from substituents on neighbouring cage vertices or, in other cases where there are no such steric constraints, from intracage electronic effects [38]. If it is accepted that such a structure is derived from an idealized closo compound, with interatomic distances still within an expected bonding range (though perhaps on the long side), then the compound should be named and numbered as closo. There is no need to introduce the new term pseudocloso. Authors may wish to bring attention to the notably 'long' interatomic distances, but it is recommended the term closo be used. If, however, the internuclear distances are such that they are outside normal bonding ranges, then structurally the compound is open and needs to be named as such, i.e. nido (or isonido) and therefore the continued use of the term pseudocloso is no longer acceptable. As with eleven-vertex cages, the numbering for any isonido species derived by stretching the corresponding twelve-vertex closo cage should retain the conventional closo system numbering.

As noted above, nomenclature is concerned with cage-atom connectivities and cage symmetry in the context of observed structures and not concerned with perceptions about electronic structure or bonding, save, in the last case, where an interatomic distance exceeds an accepted bonding range, engendering a more open cage type and therefore a different structural descriptor. Wade's Rules [5] are extensively used to correlate skeletal bonding-electron counts with observed structure. In many cases, observed structures are in agreement with structures derived using Wade's Rules. However, conflict can arise if the perceived electron count is at odds with the observed structure. In the event of such perceived conflict, it is recommended that authors specifically state that the compound in question 'is named according to its observed structure, but this is in conflict with the skeletal bonding-electron count as determined by ... and at this point the electron-counting procedure should be stated, or similar appropriate phraseology should be used. The terms precloso and hypercloso have been used by authors to differentiate closed structures held to show the 'wrong' (unusual) electron count, rather than what may be proposed to be the 'correct' electron count according to Wade's Rules. Similarly, some eleven-vertex structures with a regular standard closo structure have been described as 'isocloso' because of their unusual electron counts. These terms are no longer acceptable in this context and it is recommended that a cage with the same symmetry and connectivity as the standard deltahedral structures shown in Fig. 1 be correctly named as closo, irrespective of the perceived electron count.

\section{BN-7.4 Metal-rich cages}

There are many known cages which contain more metal atoms than boron atoms [39]. These cages are outside the scope of this document but will be studied in future projects dealing with metal clusters.

\section{Membership of sponsoring bodies}

Membership of the IUPAC Division of Chemical Nomenclature and Structure Representation for the period 2016-2017 was as follows: 
President: K.-H. Hellwich (Germany); Vice President: A. T. Hutton (South Africa); Secretary: R. S. Laitinen (Finland); Titular Members: O. Achmatowicz (Poland); T. Damhus (Denmark); P. Hodge (UK); R. T. Macaluso (USA); J. Nagy (Hungary); M. M. Rogers (USA); J. Vohlídal (Czech Republic); Associate Members: M. A. Beckett (UK); I. L. Dukov (Bulgaria); G. A. Eller (Austria); E. Mansfield (USA); M. A. Strausbaugh (USA); K. T. Taylor (USA); National Representatives: F. Aricò (Italy); A. M. da Costa Ferreira (Brazil); A. Fradet (France); H. W. Lee (Korea); T. L. Lowary (Canada); E. Nordlander (Sweden); M. Putala (Slovakia); A. P. Rauter (Portugal); J. P. van Lune (Netherlands); A. Yerin (Russia); Ex Officio: R. M. Hartshorn (New Zealand); G. P. Moss (UK).

Membership of the IUPAC Inorganic Chemistry Division for the period 2016-2017 was as follows:

President: J. Reedijk (Netherlands); Vice President: L. R. Öhrström (Sweden); Secretary: M. Leskelä (Finland); Titular Members: L. Armelao (Italy); T. Ding (China); P. Karen (Norway); R. D. Loss (Australia); D. Rabinovich (USA); T. Walczyk (Switzerland); M. Wieser (Canada); Associate Members: Y. Aziz (Malaysia); J. Colon (Puerto Rica); L. Meesuk (Thailand); K. Sakai (Japan); N. Trendafilova (Bulgaria); National Representatives: J. Darkwa (South Africa); M. Diop (France); J. Correia (Portugal); M. Hasegawa (Japan); S. Kalmykov (Russia); A. Kilic (Turkey); P. Knauth (France); G. J. Leigh (UK); S. Mathur (Germany); K. Yoon (Korea).

Funding: This manuscript was prepared in the framework of IUPAC project, Funder Id: http://dx.doi. org/10.13039/100006987, Grant Number: 2012-045-1-800.

\section{References}

[1] IUPAC. Nomenclature of Inorganic Chemistry, IUPAC Recommendations 2005, N. G. Connelly, T. Damhus, R. M. Hartshorn, A. T. Hutton (Eds.), RSC Publishing, Cambridge, UK (2005); (a) IR-6, pp. 83-110; (b) IR-6.2.3.1, pp. 89-90; (c) IR-9.2.4.2, pp. 155-160; (d) IR-10.2.3.3, pp. 210-211; (e) Table VI, p. 260; (f) Table X pp. 337-339.

[2] IUPAC. Nomenclature of Inorganic Chemistry, Recommendations 1990, G. J. Leigh (Ed.), Blackwell Scientific Publications, Oxford, UK (1990); (a) I-11, pp. 207-237; (b) pp. xx-xxi; (c) I-11.3.2.1, p. 217; (d) I-11.3.1.2, pp. 211-214; (e) I-11.3.2.5, p. 224; (f) I-11.3.2.3, pp. 222-223; (g) I-11.3.1.2, pp. 212-213; (h) I-11.3.2.4, pp. 223-224; (i) I-11.4.2, pp. 227-228; (j) I-11.4.3.1, p. 228; (k) I-11.4.3.3, pp. 231-232; (l) I-11.4.3.2, pp. 228-230; (m) I-11.4.3.3, note 11o, p. 231; (n) I-11.5.2, p. 233; (o) I-11.3.1.2, pp. 215-217; (p) I-11.3.2.7, pp. 224-225.

[3] R. M. Adams. Pure Appl. Chem. 30, 681 (1972).

[4] IUPAC. Nomenclature of Inorganic Chemistry Definitive Rules 1970, $2^{\text {nd }}$ ed., Butterworth and Co, London (1971) Chapter 11, (a) pp. 92-97; (b) p. 96; (c) p. 97; (d) pp. 93-94.

[5] K. Wade. Adv. Inorg. Chem. Radiochem. 18, 1 (1976).

[6] IUPAC. Nomenclature of Organic Chemistry. IUPAC Recommendations and Preferred Names 2013, H. A. Favre, W. H. Powell (Eds.), RSC Publishing, Cambridge, UK (2013), P-14.7.1.

[7] W. H. Powell, F. Cozzi, G. P. Moss, C. Thilgen, R. J.-R. Hwu, A. Yerin. Pure Appl. Chem. 74, 629 (2002).

[8] IUPAC. Compendium of Chemical Terminology. IUPAC Recommendations, V. Gold, K. L. Loening, A. D. McNaught, P. Selimi (Eds.), Blackwell Scientific Publication, Oxford, UK (1987), p. 11.

[9] IUPAC. Compendium of Chemical Terminology. IUPAC Recommendations, $2^{\text {nd }}$ ed., A. D. McNaught, A. Wilkinson (Eds.), Blackwell Scientific Publication, Oxford, UK (1997) and XML on-line corrected version http://goldbook.iupac.org (2006) created by M. Nic, J. Jirat, B. Kosata, updates compiled by A. Jenkins.

[10] IUPAC. Principles of Chemical Nomenclature, A Guide to IUPAC Recommendations, 2011 Edition. Edited by G. J. Leigh, RSC Publishing, Cambridge UK (2011), Table 6.2, p. 63.

[11] M. A. Beckett, N. N. Greenwood, J. D. Kennedy, M. Thornton-Pett. J. Chem. Soc., Dalton Trans. 1119 (1985).

[12] J. P. Sheehan, T. R. Spalding, G. Ferguson, J. F. Gallagher, B. Kaitner, J. D. Kennedy. J. Chem. Soc., Dalton Trans. 35 (1993).

[13] M. A. Beckett, J. E. Crook, N. N. Greenwood, J. D. Kennedy. J. Chem. Soc., Dalton Trans. 1879 (1986).

[14] M. A. Beckett, J. E. Crook, N. N. Greenwood, J. D. Kennedy. J. Chem. Soc., Chem. Commun. 1228 (1983).

[15] M. A. Beckett, J. E. Crook, N. N. Greenwood, J. D. Kennedy, W. S. McDonald. J. Chem. Soc., Chem. Commun. 552 (1982).

[16] M. A. Beckett, N. N. Greenwood, J. D. Kennedy, P. A. Salter, M. Thornton-Pett. J. Chem. Soc., Chem. Commun. 556 (1986).

[17] J. D. Kennedy. Coord. Chem. Rev. 323, 71 (2016).

[18] J. M. Oliva, J. Rué, D. Hnyk, J. D. Kennedy, V. R. Rosenfeld. Croat. Chem. Acta 86, 485 (2013). 
[19] N. N. Greenwood, A. Earnshaw. Chemistry of the Elements, Chapter 6, p. 177, Pergamon Press, Oxford, UK (1984).

[20] H.-J. Yao, C.-H. Hu, J. Sun, R.-S. Jin, P.-J. Zheng, J. Bould, R. Greatrex, J. D. Kennedy, D. Ormsby, M. Thornton-Pett. Collect. Czech. Chem. Commun. 64, 927 (1999).

[21] J. Bould, W. Clegg, S. J. Teat, L. Barton, N. P. Rath, M. Thornton-Pett, J. D. Kennedy. Boron Chemistry at the Millennium, special edition of Inorg. Chim. Acta 289, 95 (1999).

[22] D. L. V. K. Prasad, E. D. Jemmis. Phys. Rev. Lett. 100, No. 166504 (2008).

[23] J. B. Casey, W. J. Evans, W. H. Powell. Inorg. Chem. 20, 1333 (1981).

[24] L. D. Brown, W. N. Lipscomb. Inorg. Chem. 16, 2989 (1977).

[25] J. Poater, M. Sola, C. Vinas, F. Teixidor. Chem. Eur. J. 22, 7347 (2016).

[26] R. N. Grimes. Carboranes, $2^{\text {nd }}$ ed., Academic Press, Elsevier, Oxford, UK (2011).

[27] L. Deng, H.-S. Chan., Z. Xie. Angew. Chem. Int. Ed. 44, 2128 (2005); Angew. Chem. 117, 2166 (2005).

[28] D. K. Roy, B. Mondal, P. Shankhari, R. S. Angu, K. Geetharani, S. M. Mobin, S. Ghosh. Inorg. Chem. 52, 6705 (2013).

[29] D. K. Roy, S. K. Bose, R. S. Angu, B. Mondal, V. Ramkumar, S. Ghosh. Angew. Chem. Int. Ed. 52, 3222 (2013); Angew. Chem. 125, 3304 (2013).

[30] P. von Rague Schleyer, K. Najafian, A. M. Mebeb. Inorg. Chem. 37, 6765 (1998).

[31] A. Burke, D. Ellis, B. T. Giles, B. E. Hodson, S. A. Macgregor, G. M. Rosair, A. J. Welch. Angew Chem. Int. Ed. 42, 225 (2003); Angew. Chem. 115, 235 (2003).

[32] A. McAnaw, G. Scott, L. Elrick, G. M. Rosair, A. J. Welch. Dalton Trans. 42, 645 (2013).

[33] A. McAnaw, M. E. Lopez, D. Ellis, G. M. Rosair, A. J. Welch. Dalton Trans. 42,671 (2013).

[34] L. Deng, J. Zhang, H.-S. Chan, Z. Xie. Angew. Chem. Int. Ed. 45, 4309 (2006); Angew. Chem. 118, 4415 (2006).

[35] R. D. McIntosh, D. Ellis, G. M. Rosair, A. J. Welch. Angew. Chem. Int. Ed. 45, 4313 (2006); Angew. Chem. 118, 4419 (2006).

[36] J. B. Casey, W. J. Evans, W. H. Powell. Inorg. Chem. 22, 2236 (1983).

[37] E. G. Kononova, L. A. Leites, S. S. Bukalov, I. V. Pisareva, I. T. Chizhevsky, J. D. Kennedy, J. Bould. Eur. J. Inorg. Chem. 4911 (2007).

[38] J. Bould, J. D. Kennedy. J. Organomet. Chem. 749, 163 (2014).

[39] L. Barton, D. K. Srivastava. In Comprehensive Organometallic Chemistry II, Vol 1, Ch 8, Vol. C. E. Housecroft (Ed.), Eds. in Chief E. W. Abel, F. G. A. Stone, G. Wilkinson, pp. 275-372, Pergamon, Oxford, UK (1995). 